\title{
Global Influence of Tropical Pacific Variability with Implications for Global Warming Slowdown $\mathscr{}$
}

\author{
CHUAN-YANG WANG \\ Physical Oceanography Laboratory, Cooperation and Innovation Center for \\ Marine Science and Technology (CIMST), Ocean University of China, and Qingdao \\ National Laboratory for Marine Science and Technology, Qingdao, China \\ SHANG-PING XIE \\ Scripps Institution of Oceanography, University of California, San Diego, La Jolla, California, \\ and Physical Oceanography Laboratory, Cooperation and Innovation Center for Marine Science and \\ Technology (CIMST), Ocean University of China, and Qingdao National Laboratory for \\ Marine Science and Technology, Qingdao, China \\ YU KOSAKA \\ Research Center for Advanced Science and Technology, University of Tokyo, Tokyo, Japan

\section{QINYU LIU AND XIAO-TONG ZHENG} \\ Physical Oceanography Laboratory, Cooperation and Innovation Center for Marine Science and \\ Technology (CIMST), Ocean University of China, and Qingdao National Laboratory for Marine \\ Science and Technology, and Key Laboratory of Ocean-Atmosphere Interaction and \\ Climate in Universities of Shandong, Ocean University of China, Qingdao, China
}

(Manuscript received 18 July 2015, in final form 23 December 2016)

\begin{abstract}
The impact of internal tropical Pacific variability on global mean surface temperature (GMST) is quantified using a multimodel ensemble. A tropical Pacific index (TPI) is defined to track tropical Pacific sea surface temperature (SST) variability. The simulated GMST is highly correlated with TPI on the interannual time scale but this correlation weakens on the decadal time scale. The time-scale dependency is such that the GMST regression equation derived from the observations, which are dominated by interannual variability, would underestimate the magnitude of decadal GMST response to tropical Pacific variability. The surface air temperature response to tropical Pacific variability is strong in the tropics but weakens in the extratropics. The regression coefficient of GMST against TPI shows considerable intermodel variations, primarily because of differences in high latitudes. The results have important implications for the planned intercomparison of pacemaker experiments that force Pacific variability to follow the observed evolution. The model dependency of the GMST regression suggests that in pacemaker experiments-model performance in simulating the recent "slowdown" in global warming - will vary substantially among models. It also highlights the need to develop observational constraints and to quantify the TPI effect on the decadal variability of GMST.

Compared to GMST, the correlation between global mean tropospheric temperature and TPI is high on both interannual and decadal time scales because of a common structure in the tropical tropospheric temperature response that is upward amplified and meridionally broad.
\end{abstract}

Supplemental information related to this paper is available at the Journals Online website: http://dx.doi.org/10.1175/ JCLI-D-15-0496.s1.

Corresponding author e-mail: Shang-Ping Xie, sxie@ucsd.edu

\section{Introduction}

The increase of global mean surface temperature (GMST) since the industrial revolution is primarily caused by radiative forcing due to increased greenhouse gas concentrations in the atmosphere (Hansen et al. 2005; Trenberth et al. 2009; Bindoff et al. 2013). For 
1998-2013, the GMST increase slowed down despite the continued rise in greenhouse gas concentrations (Easterling and Wehner 2009; Fyfe et al. 2016). During the surface warming slowdown, a radiation imbalance of net downward energy flux is observed at the top of the atmosphere (Hansen et al. 2005; Trenberth et al. 2009; Loeb et al. 2012), while the interior ocean continues to warm (Domingues et al. 2008; Lyman et al. 2010; Gleckler et al. 2012; Levitus et al. 2012; Balmaseda et al. 2013). This suggests a vertical redistribution of ocean heat content (Meehl et al. 2011; Chen and Tung 2014; Liu et al. 2016).

Both internal variability and external forcings contribute to the surface warming slowdown. External factors, such as the early twenty-first-century increase in volcanic aerosols (Solomon et al. 2011; Santer et al. 2014), recent increases in anthropogenic sulfur aerosols (Kaufmann et al. 2011), and the minimum in solar irradiance during the last solar cycle (Kopp and Lean 2011 have contributed to the slowdown. Observations and model simulations suggest that internal variability of the climate system is another major contributor (e.g., Meehl et al. 2011, 2013; Trenberth 2015; Xie et al. 2016; Fyfe et al. 2016).

Regarding internal climate variability, there are debates on which regions are most important for GMST change during the global warming slowdown period. Various studies have emphasized the role of the North Atlantic Ocean (Tung and Zhou 2013; Chylek et al. 2014) and/or the Pacific Ocean (Foster and Rahmstorf 2011; Meehl et al. 2011; Brown et al. 2015; Dai et al. 2015; Steinman et al. 2015; Trenberth 2015). Recent modeling studies indicate that the tropical Pacific Ocean plays a vital role in the global warming slowdown. By forcing sea surface temperature (SST) or wind stress variability over the tropical Pacific to follow the observed evolution, climate models have successfully simulated many key features of the global warming slowdown (Kosaka and Xie 2013; England et al. 2014; Watanabe et al. 2014). Specifically, the global warming slowdown is likely to be associated with a La Niña-like cooling pattern in the tropics (Meehl et al. 2011; Kosaka and Xie 2013). Pacific OceanGlobal Atmosphere (POGA) pacemaker experiments are useful tools for evaluating the contribution of the internally generated tropical Pacific cooling to the global warming slowdown (Kosaka and Xie 2016). Such POGA experiments have been conducted with only a very limited number of general circulation models (GCMs). The skills of the POGA experiment in reproducing the global warming slowdown need to be evaluated in other GCMs.

The present study investigates the correlation and regression relationships between tropical Pacific SST variability and global atmospheric temperature by using phase 5 of the Coupled Model Intercomparison Project (CMIP5; Taylor et al. 2012) multimodel ensemble. To study the internal variability featured in the POGA experiment, we analyze the results from unforced control runs with external forcings held fixed at preindustrial levels. The skills in reproducing tropical Pacific SST-GMST correlation and regression may help evaluate the performance of each model in POGA simulations with regard to decadal modulations of GMST changes. By separating internal variability into interannual and decadal components, we show that the impact of tropical Pacific SST on GMST is larger in magnitude on decadal time scales than on interannual time scales in a multimodel mean sense. This time-scale dependency has implications for observational estimates of the Pacific effect on GMST. The relatively short instrumental record is dominated by interannual variability, while decadal variability is more relevant to the global warming slowdown (Tung and Zhou 2013; Dai et al. 2015). Without proper filtering and treating the interannual and decadal components separately, applying the observed tropical Pacific SST-GMST relationship in attribution studies may underestimate the tropical Pacific effect on the decadal time scale. Our analysis also reveals large intermodel variations in the tropical Pacific effect on both interannual and decadal time scales. This suggests that GCMs may have substantial differences in the level of skill with which they simulate the slowdown in global warming in tropical Pacific pacemaker experiments.

We extend our analysis to global mean tropospheric temperature (TT), for which the time-scale dependency of the tropical Pacific effect is weak. This is because the tropical contribution dominates the global tropospheric temperature response and because dynamic adjustments flatten the tropical TT response meridionally on both interannual and decadal time scales.

The rest of this paper is organized as follows. Section 2 discusses the data used in this study and introduces an index to characterize tropical Pacific SST variability. Section 3 examines the correlation and regression relationships between tropical Pacific SST and global surface air temperature (SAT) at multiple spatial and temporal scales. Intermodel variation in these relationships and its possible implications are also discussed in this section. Section 4 shifts the focus onto the TT response to tropical Pacific SST variability. While our analysis is based on unforced control runs, observed tropical Pacific SST variability includes both forced and internal components. Section 5 evaluates the effect of model errors in simulating the forced tropical Pacific variability on the estimates of the internal component. Thus, our study aids 
TABLE 1. CMIP5 models adopted in this analysis with their interannual $\left(\sigma_{\text {IAV }}\right)$ and decadal $\left(\sigma_{\text {IDV }}\right)$ standard deviations of TPI. See appendix B for the definition of the "Strong" and "weak" groups.

\begin{tabular}{lllll}
\hline \multicolumn{1}{c}{ Model } & \multicolumn{2}{c}{$\sigma_{\text {IAV }}(\mathrm{K})$} & \multicolumn{2}{c}{$\sigma_{\text {IDV }}(\mathrm{K})$} \\
\hline ACCESS1.3 & 0.28 & Weak & 0.17 & Strong \\
BCC_CSM1.1 & 0.21 & & 0.08 & \\
CCSM4 & 0.45 & Strong & 0.13 & Weak \\
CMCC-CMS & 0.36 & Strong & 0.12 & Weak \\
CSIRO Mk3.6.0 & 0.30 & Weak & 0.17 & Strong \\
CanESM2 & 0.36 & Strong & 0.13 & Weak \\
FGOALS-g2 & 0.30 & Strong & 0.09 & Weak \\
GFDL CM3 & 0.40 & & 0.10 & \\
GFDL-ESM2G & 0.34 & & 0.13 & \\
GFDL-ESM2M & 0.50 & Strong & 0.14 & Weak \\
HadGEM2-AO & 0.28 & Weak & 0.24 & Strong \\
HadGEM2-ES & 0.28 & Weak & 0.23 & Strong \\
INM-CM4.0 & 0.18 & Weak & 0.09 & Weak \\
IPSL-CM5A-LR & 0.29 & Weak & 0.14 & Weak \\
MIROC-ESM & 0.20 & Weak & 0.19 & Strong \\
MIROC5 & 0.36 & Strong & 0.18 & Strong \\
MPI-ESM-LR & 0.33 & Strong & 0.21 & Strong \\
MPI-ESM-MR & 0.28 & Weak & 0.19 & Strong \\
MPI-ESM-P & 0.31 & Strong & 0.19 & Strong \\
MRI-CGCM3 & 0.20 & Weak & 0.09 & Weak \\
NorESM1-M & 0.36 & Strong & 0.12 & Weak \\
\hline
\end{tabular}

the analysis of the planned intercomparison of pacemaker experiments under CMIP6 (Boer et al. 2016). Section 6 provides a summary of our results.

\section{Data and methods}

\section{a. Data}

We use simulation outputs from 21 CMIP5 models. Results are from both preindustrial control (CTRL) and historical (HIST) experiments (Table 1). Without yearto-year variability in radiative forcing, the control experiments yield internal variability of the climate system. Monthly SAT, SST, and atmospheric temperature at discrete pressure levels are used in this research. We also analyze the POGA experiments [see Kosaka and Xie (2016) for a detailed description of the experimental design] performed with the Geophysical Fluid Dynamics Laboratory (GFDL) Climate Model, version 2.1 [GFDL CM2.1 (CM2.1); Delworth et al. 2006]. The CM2.1 POGA ensemble consists of 10 runs. We use the ensemble mean of $20 \mathrm{CM} 2.1$ HIST runs to remove external signals from POGA simulations (see sections $2 \mathrm{c}$ and 5).

To compare with observations, we use monthly SAT and SST data from the Japanese 55-year Reanalysis (JRA-55; Kobayashi et al. 2015) for 1958-2013, the European Centre for Medium-Range Weather Forecasts interim reanalysis (ERA-Interim; Dee et al. 2011) for 1979-2013, and the National Centers for Environmental
Prediction-National Center for Atmospheric Research (NCEP-NCAR) reanalysis (NCEP reanalysis; Kalnay et al. 1996) for 1948-2013. The corresponding SST data analyzed with the NCEP reanalysis and JRA are based on the Extended Reconstructed SST, version 3b (ERSST.v3b), dataset (Smith et al. 2008).

We use the first $500 \mathrm{yr}$ for CMIP5 CTRL simulations and the period of 1871-2005 for the CMIP5 HIST simulations. The CM2.1 HIST and POGA experiments cover the period of 1871-2005, after a 10-yr spinup. For reanalysis products, the whole available time span is used. SST from models and observations is interpolated onto a $1^{\circ} \times 1^{\circ}$ grid. All variables are annually averaged in the ENSO year from July to the following June. A 61-point Lanczos bandpass filter with a half-power point at $10 \mathrm{yr}$ and $50 \mathrm{yr}$ is applied to all detrended yearly variables at each grid point to isolate the decadal variability. We also use a high-pass filter with a half-power point at $10 \mathrm{yr}$ to isolate the interannual variability. While previous studies have noted errors from CMIP5 models in simulating decadal variability (e.g., Brown et al. 2015; Laepple and Huybers 2014; Santer et al. 2011, 2013), an intermodel comparison is useful for evaluating to what degree the performance of POGA experiment is model dependent.

\section{b. The tropical Pacific index}

Empirical orthogonal function (EOF) decomposition is widely used to extract dominant modes of internal variability. For each mode, a spatial pattern (EOF) and the corresponding principal component (PC) time series can be obtained. Figures $1 \mathrm{a}, \mathrm{b}$ show the spatial pattern of the leading mode (EOF1, calculated with unnormalized SST) of tropical Pacific SST in the CCSM4 CTRL simulation on interannual and decadal time scales, respectively. On both time scales, SST is characterized by a maximum warming located in the central and eastern equatorial Pacific. This positive anomaly decreases poleward and turns negative in the subtropical regions. The cooling shows a boomeranglike pattern in the western Pacific Ocean. The dominant mode of tropical Pacific SST variability is ENSO on the interannual time scale and the Pacific decadal oscillation (Zhang et al. 1997; Power et al. 1999) on the decadal time scale. Patterns in other models (not shown) are similar, with slight differences regarding the westward extension of the equatorial maximum in the west Pacific Ocean, which will be discussed in the next section.

The interannual and decadal modes share a similar spatial pattern except for a much sharper peak at the equator for the interannual mode (Zhang et al. 1997). We define a tropical Pacific index (TPI) as the spatial average 


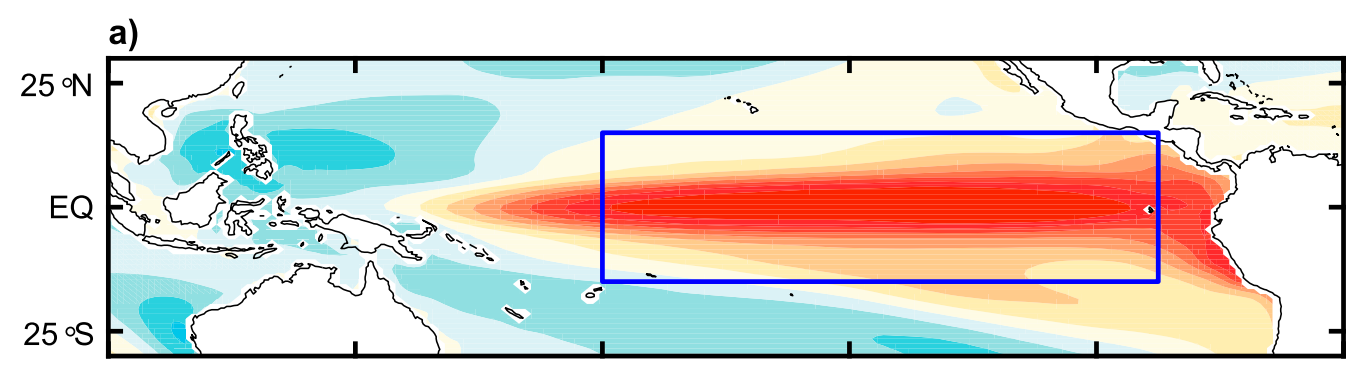

b)
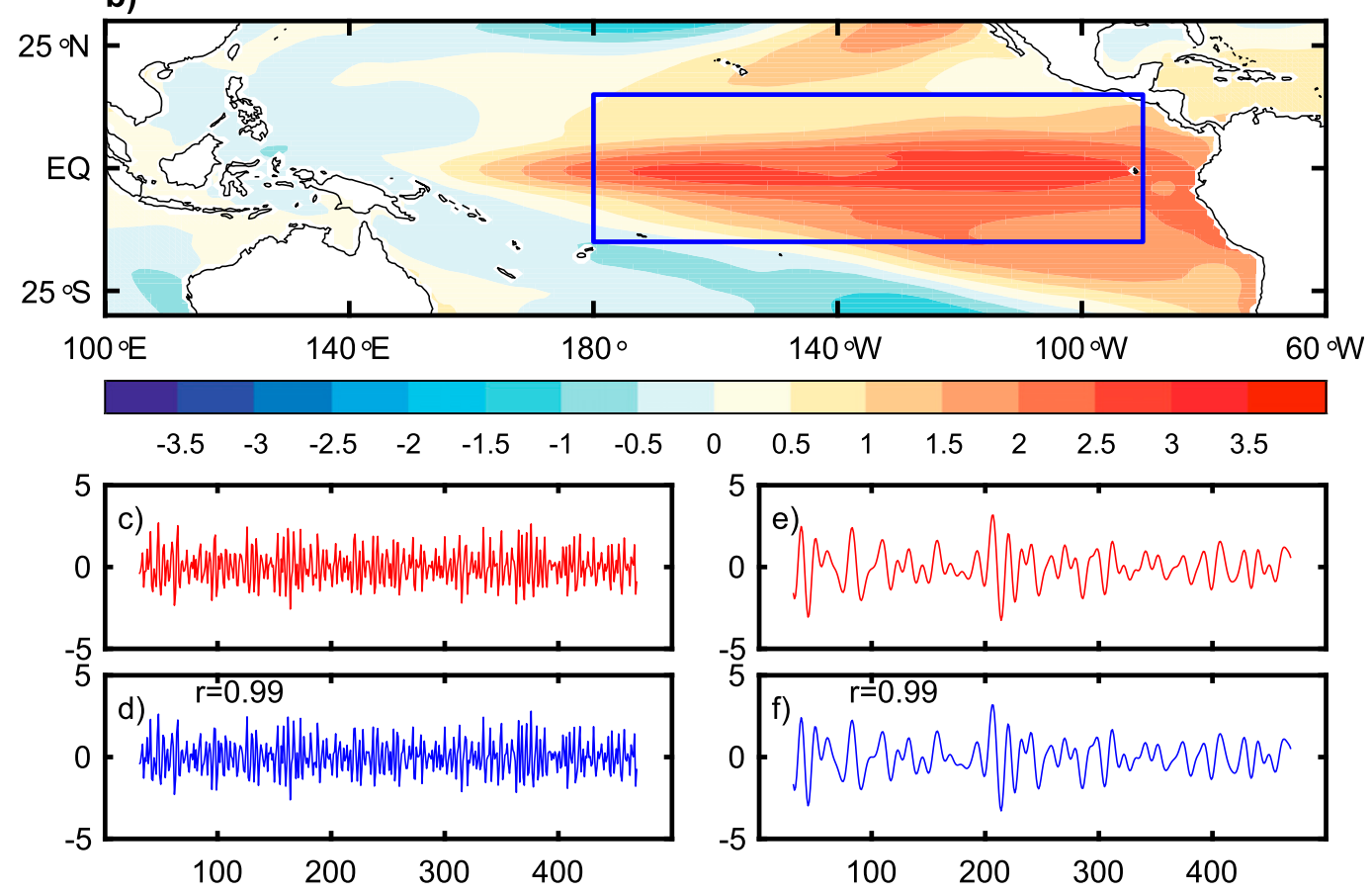

FIG. 1. (a) Spatial pattern (K) and (c) the normalized time series of the leading mode of tropical Pacific SST for interannual variability. (b),(e) As in (a) and (c), respectively, but for decadal variability. (d),(f) Normalized TPIs for interannual and decadal variability, which are defined as the spatial average of the SST anomaly in $15^{\circ} \mathrm{S}-15^{\circ} \mathrm{N}$, $180^{\circ}-90^{\circ} \mathrm{W}$ [blue box in (a) and (b) Correlation coefficient values with the time series of (c) and (e) are indicated in (d) and (f), respectively.

of eastern and central Pacific SST from $15^{\circ} \mathrm{S}$ to $15^{\circ} \mathrm{N}$ and $180^{\circ}$ eastward to $90^{\circ} \mathrm{W}$ (the region in the blue box in Figs. 1a,b). This is roughly the region where Kosaka and Xie $(2013,2016)$ restore SST in the POGA experiment. On both interannual and decadal time scales, the correlation coefficients between TPI (Figs. 1d,f) and tropical Pacific SST PC1 (Figs. 1c,e) exceed 0.9 and achieve statistical significance at the $1 \%$ level or better. Thus, the TPI captures the temporal behavior of the dominant mode of tropical Pacific variability.

The power spectrum of the unfiltered TPI peaks at periods between 1.5 and $8 \mathrm{yr}$ in the CTRL simulations, broadly consistent with the observed periods of ENSO at 2-7yr. See Bellenger et al. (2014) for a comprehensive evaluation of ENSO simulations. While only two models (HadGEM2-AO and HadGEM2-ES) display a significant decadal spectral peak for the unfiltered TPI, the spectra of the low-pass filtered TPI peak at around $20-60 \mathrm{yr}$ across the CMIP5 ensemble.

\section{c. Internal variability and tropical Pacific effect}

The tropical Pacific effect $a$ can be quantified using a simple regression model: $T=a \times P$, in which $P$ denotes the TPI anomaly and $T$ denotes the SAT or TT anomaly. The regression coefficient $a$ represents the magnitude of the $T$ anomaly associated with a TPI change of $1 \mathrm{~K}$. In this paper, we examine the tropical Pacific effect of the internal variability.

In the POGA experiments, we extract the internal variability by subtracting the ensemble mean of CM2.1 HIST runs from each POGA run. We extract the internal signal from reanalysis products and HIST simulations by 
a) IAV: POGA

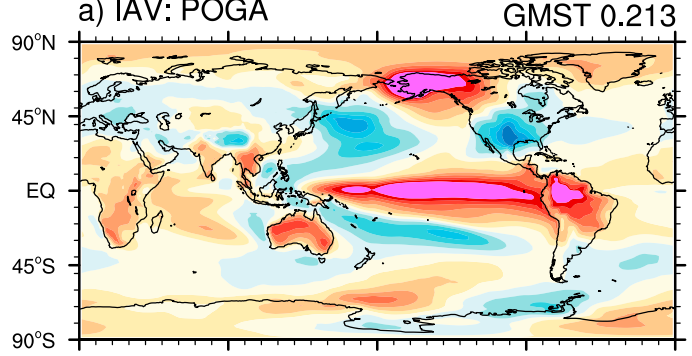

C) IAV: CTRL

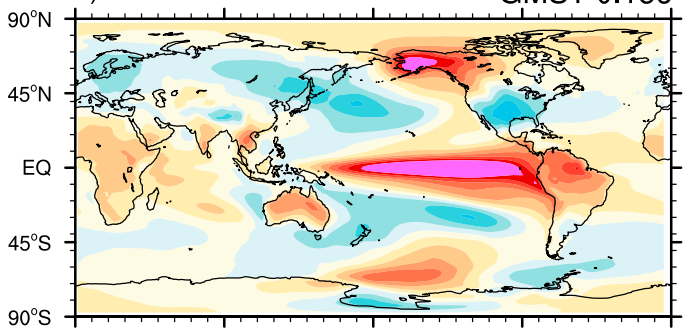

e) IAV: HIST

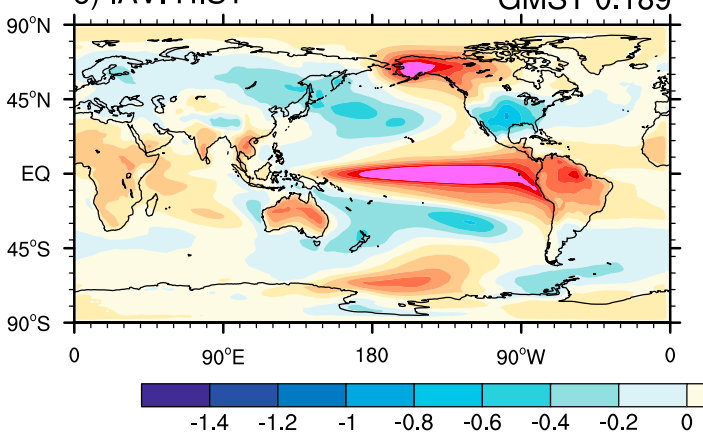

b) IDV: POGA
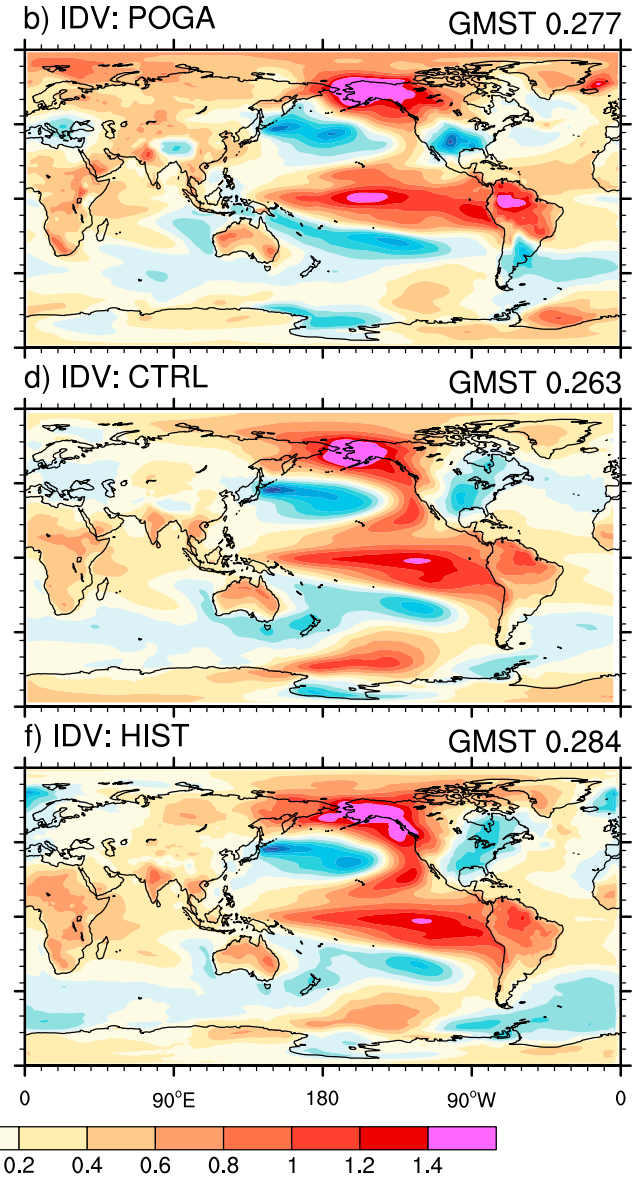

FIG. 2. Regression coefficients $\left(\mathrm{K} \mathrm{K}^{-1}\right.$ ) of gridded SAT against TPI on the (a),(c),(e) interannual (IAV) and (b),(d),(f) decadal (IDV) time scales in the (a),(b) POGA, (c),(d) CMIP5 CTRL, and (e),(f) CMIP5 HIST simulations.

applying the method of Dai et al. (2015), which regresses out the radiatively forced response against the multimodel mean GMST anomaly. Without year-to-year variability in external forcings, the CTRL simulations comprise only internal variability.

The method we used to extract internal variability proves effective with POGA and HIST simulations. The regression coefficient shows a similar spatial distribution across HIST, CTRL, and POGA, on both interannual and decadal time scales (Fig. 2). As CTRL simulations are available for much longer periods $(\geq 500 \mathrm{yr})$ than HIST, we chose CTRL simulations to analyze the tropical Pacific effect of the internal variability.

Term $a$ is somewhat sensitive to the choice of methods to remove externally forced signals, especially on the decadal time scale. It is valid to estimate the internal variability from the POGA and HIST simulations only if the HIST ensemble mean accurately simulates the externally forced component. In practice, errors in simulating the forced component introduce errors in estimating internal variability. Section 5 shows that the latter errors are small and that the CTRL results to be presented in the following two sections are a good approximation of the tropical Pacific effect on GMST in POGA. Appendix A compares the methods in removing external signals.

Because of the limited temporal coverage of the observations, the tropical Pacific effect in the reanalysis products is difficult to quantify on the decadal time scale. For this reason, we analyze both the interannual and decadal variability in the CMIP5 ensembles but only the interannual variability in the reanalysis.

\section{SAT correlation and regression}

\section{a. GMST}

The correlation coefficients between GMST and TPI in the CTRL simulations range from 0.60 to 0.89 for interannual variability and from 0.42 to 0.86 for decadal variability (Fig. 3a). In the reanalyses, the interannual correlation coefficients are $0.52,0.69$, and 0.74 for ERA-Interim, JRA-55, and NCEP-NCAR reanalysis, 

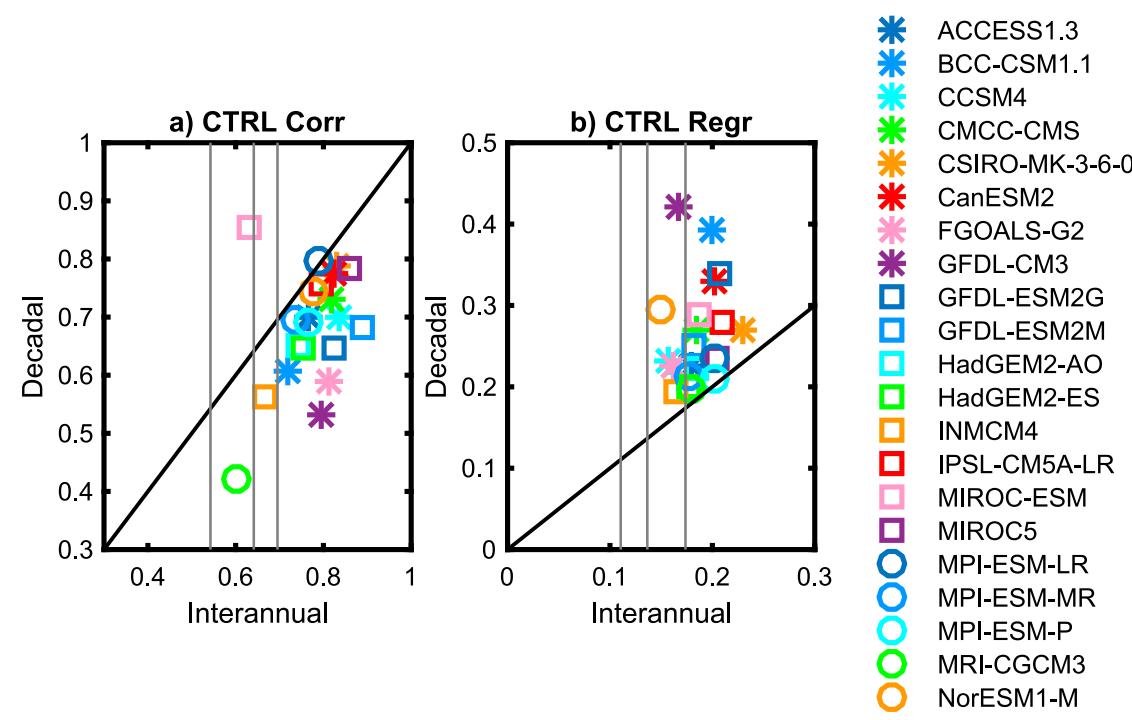

FIG. 3. Scatter diagram between the decadal and interannual (a) correlation and (b) regression $\left(\mathrm{K} \mathrm{K}^{-1}\right)$ coefficients of GMST against TPI in 21 CMIP5 CTRL simulations. Vertical gray lines denote the three reanalysis results on the interannual time scale.

respectively. The correlation and regression coefficients for the reanalysis products vary with temporal coverage. The statistical results of the three reanalyses are different, especially on the polar regions, even though the longest common period is analyzed (1979-2013; see Figs. S1 and $\mathrm{S} 2$ in the supplemental material file JCLI-D-15-0496s1). The correlation coefficients in the CTRL simulations are larger than in the reanalyses. The correlation coefficients peak at zero lag for the annual averaged data, while the monthly GMST-TPI correlation coefficients reach maxima with TPI leading GMST by $2-3$. Hereafter, correlation and regression coefficients are all based on annual averaged data if not otherwise stated. The correlation coefficients in all the models and reanalyses exceed the 99\% confidence level based on a second-order autoregressive (AR2) model. Correlations are calculated with 10000 synthetic TPI and GMST time series after filtering. We take the 0.5 th and 99.5 th percentiles as the confidence level. The TPI-GMST correlation shows a time-scale dependency: the GMST is more closely tied with tropical Pacific variability on the interannual than the decadal time scale in the CTRL simulations.

The TPI-GMST correlation is model dependent. For interannual variability, correlation coefficients reach a maximum in GFDL-ESM2M (0.89) and a minimum in MRI-CGCM3 (0.60). For decadal variability, the maximum correlation coefficient is in MIROC-ESM (0.76) and the minimum is in MRI-CGCM3 (0.42). The intermodel spread of the decadal correlation coefficients is larger on the decadal than interannual time scale. On the interannual time scale, the TPI-GMST correlation is modulated by the ENSO amplitude (measured by the TPI standard deviation; appendix B). This modulation is weak on the decadal time scale.

The regression coefficients of GMST against tropical Pacific SST also display strong intermodel and time-scale sensitivity (Fig. 3b). The multimodel mean interannual regression coefficient is around 0.19 , while the decadal regression coefficient is $0.26-\mathrm{a} 41 \%$ difference. Even if the three outliers (GFDL CM3, GFDL-ESM2G, BCC CSM1.1) with the largest decadal regression coefficients are excluded, the mean GMST response is still $31 \%$ greater for decadal than interannual variability. Regarding intermodel variation, the decadal TPI-GMST regression coefficients can be as high as 0.41 in GFDL CM3 and as low as 0.19 in MPI-ESM-MR. The intermodel spread in the decadal regression coefficient is larger than the interannual counterpart by a factor of 3 (a factor of 2 if the three models with the largest decadal regression are excluded).

The regression and correlation relationship between TPI and GMST varies as a function of time scale. This indicates that applying the interannual regression coefficients to decadal variability underestimates the tropical Pacific effect on GMST. Large intermodel variations in the decadal regression coefficient suggest that POGA experiments would show a wide range of performance in reproducing key observed features of the recent surface warming slowdown.

\section{b. Zonal mean SAT}

To understand why the statistical relationship between tropical Pacific SST and GMST varies among models and 

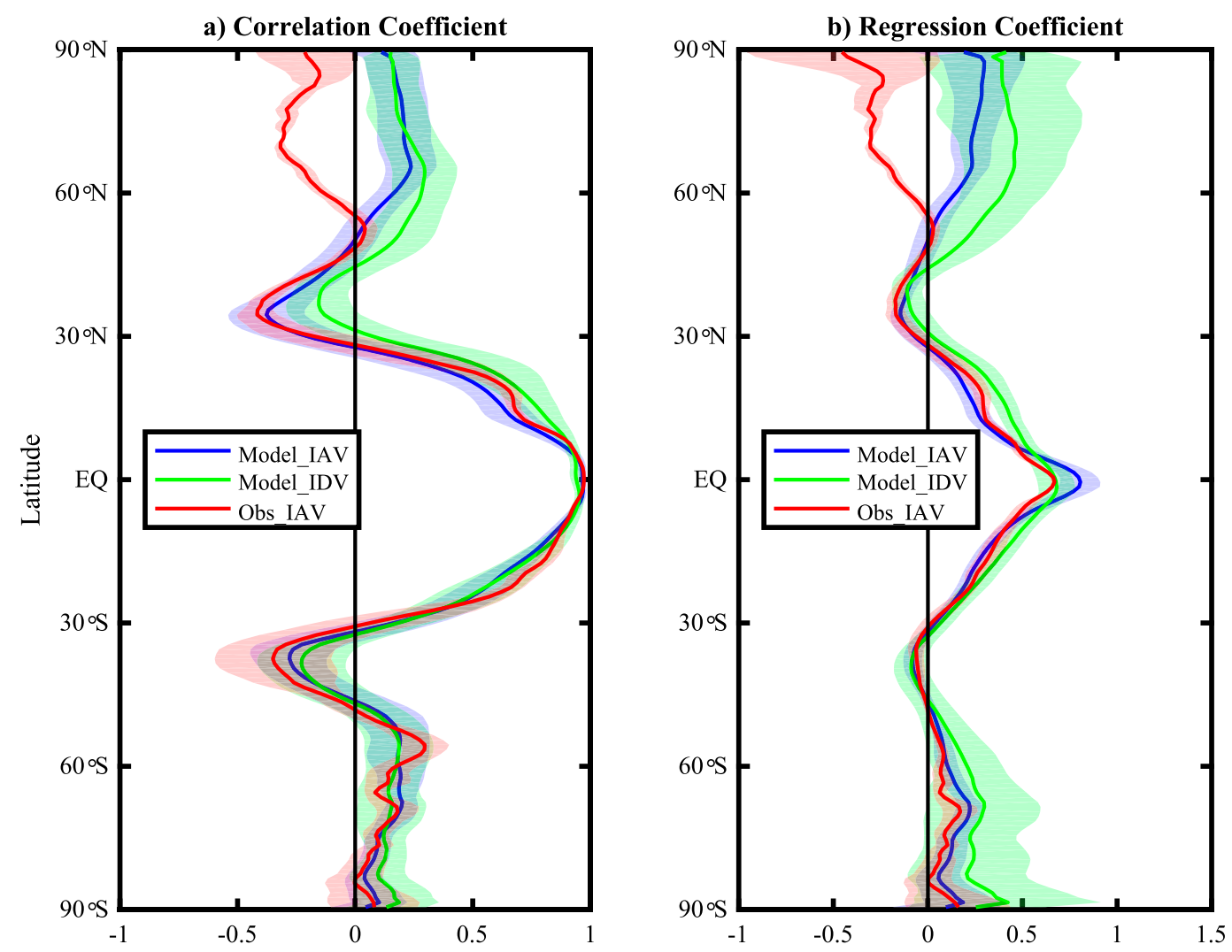

FIG. 4. Meridional profiles of the (a) correlation and (b) regression $\left(\mathrm{K} \mathrm{K}^{-1}\right)$ coefficients of zonal mean SAT against TPI. Solid color lines represent the ensemble mean of correlation-regression coefficients based on the individual models or reanalyses: green for decadal variability (IDV); blue and red for interannual variability (IAV) in the model and reanalysis, respectively. Shadings denote the intermodel variation defined as the standard deviations of the model or reanalysis ensembles.

time scales, a closer look into the meridional structure is necessary. Figure 4 shows the meridional profiles of the correlation and regression coefficients between TPI and zonal mean SAT. In reanalyses, the interannual correlation coefficients peak at the equator and decrease with latitude, reaching minima at around $35^{\circ} \mathrm{N}$ in the Northern Hemisphere and at $40^{\circ} \mathrm{S}$ in the Southern Hemisphere (Fig. 4a). Correlation coefficients are small at the poles. The multimodel averaged correlation between zonal mean SAT and TPI in the CTRL simulations is similar to the reanalysis result at all latitudes. The exception is in the Northern Hemispheric polar and subpolar regions, where the correlation is positive in the CTRL but negative in the reanalyses (Fig. 4a). The multimodel averaged decadal correlation coefficient shows a meridional profile similar to that of the interannual results. On both time scales, the correlation is high in the tropics and weakens poleward, indicating that the influence of tropical Pacific internal variability is mostly confined to low latitudes.

Figure $4 \mathrm{~b}$ shows the meridional profiles of regression between the zonal mean SAT and the TPI. As in the case of the correlation coefficients, there is a peak on the equator with minima in the midlatitudes for reanalyses and GCMs on both interannual and decadal time scales. The interannual regressions of CTRL and reanalyses show marked differences at high latitudes in the Northern Hemisphere. At the equator, the ensemble mean of the interannual regression coefficients is greater than those in the reanalyses. Models overestimate the contribution of tropical Pacific SST to the equatorial SAT possibly because of the overly westward-extended cold tongue (Fig. 5b; discussed in section 3c). The equatorial peak of the decadal regression is slightly smaller than the interannual one, but the decadal regression decays more slowly poleward from the equator with a consistently larger value than interannual regression in the tropics (Fig. 4b). In the Northern Hemisphere high latitudes, the decadal multimodel averaged regression coefficient is also larger than the interannual coefficient.

The intermodel spread of correlation and regression coefficients in the tropics is small on the interannual time scale. The small intermodel variation and the 
a) IAV: JRA

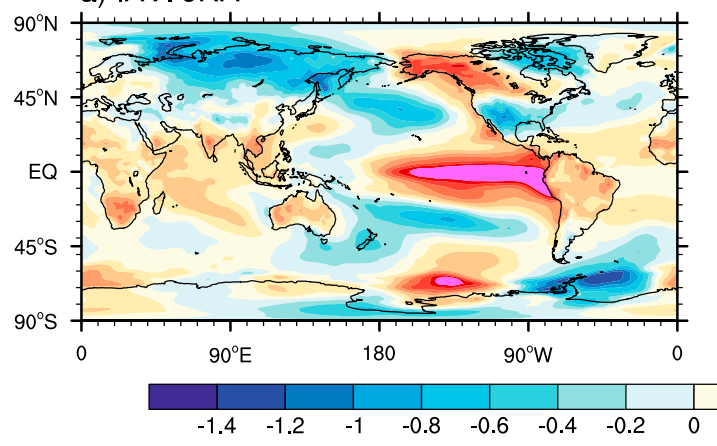

b) IAV DIFF: CTRL - JRA

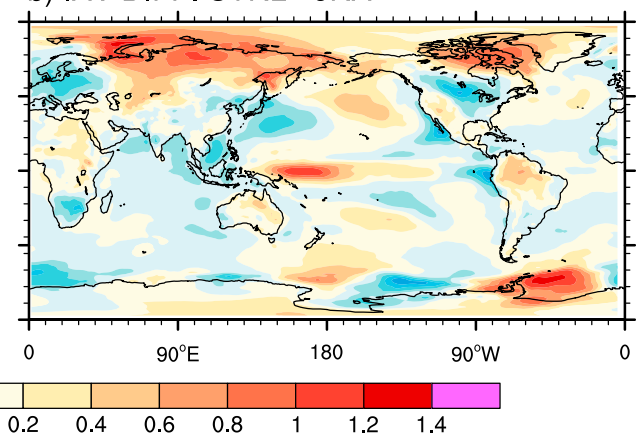

FIG. 5. (a) Regression coefficients $\left(\mathrm{K} \mathrm{K}^{-1}\right.$ ) of gridded SAT against TPI of JRA, and (b) the difference between JRA and the multimodel mean of regressions based on 21 CMIP5 models for interannual variability (Fig. 2c).

similar meridional correlation profiles between the reanalyses and CMIP5 ensemble suggest that CMIP5 models are capable of capturing the global impact of tropical Pacific variability on the interannual time scale. On the decadal time scale, the ensemble spread of correlation and regression coefficients is also small in the tropics. For regression coefficients, the spread increases noticeably in the extratropics. The large intermodel uncertainty in the GMST regression coefficients implies that the tropical impact on high-latitude SAT varies strongly among models.

The tropical Pacific effect on GMST is mostly confined to the tropics $\left(30^{\circ} \mathrm{S}-30^{\circ} \mathrm{N}\right)$ on both interannual and decadal time scales (Fig. 4b). On the decadal time scale, the Northern Hemisphere extratropical contribution to GMST is large compared to the interannual time scale but remains small compared to the tropical contribution. One possible explanation is that the horizontal pattern of the tropical effect on SAT is not zonally uniform in the extratropical regions (Fig. 2). Positive and negative regression coefficients somewhat cancel each other, resulting in a much weaker contribution to the GMST response. A detailed discussion of the spatial pattern is presented in section $3 \mathrm{c}$.

While the tropical Pacific effect on high-latitude SAT variability is limited in the abovementioned annual mean analysis, it becomes large on the decadal time scale during boreal winter (Fig. 6). This seasonal dependency is evident in a number of models (14 out of 21 in this analysis). In boreal winter, transient eddy activity intensifies and transports more energy and heat from the tropics to higher latitudes in the Northern Hemisphere (Trenberth et al. 2002; Fasullo and Trenberth 2008), enhancing the Pacific effect on the Northern Hemisphere high latitudes. This result is in agreement with Kosaka and Xie (2013) that the global warming slowdown is most pronounced in boreal winter. Our results suggest that more than half of the models analyzed here would be able to reproduce the seasonality of the TPI's influence on SAT in POGA experiments.

\section{c. Global regression pattern}

Figures 2c,d, 5a display the patterns of SAT regression against TPI in the CTRL ensemble and JRA. An El Niño-like pattern can be found in both JRA and the CMIP5 ensemble on the interannual time scale (Figs. 5a, 2c, respectively). The model ensemble has larger regression coefficients over the western tropical Pacific (Fig. 5b) compared to JRA, indicating that models overestimate the westward extent of ENSO SST variability. In the Arctic Ocean, observations display a negative response but models show a moderate positive response. Finally, in western Europe, the negative response is much

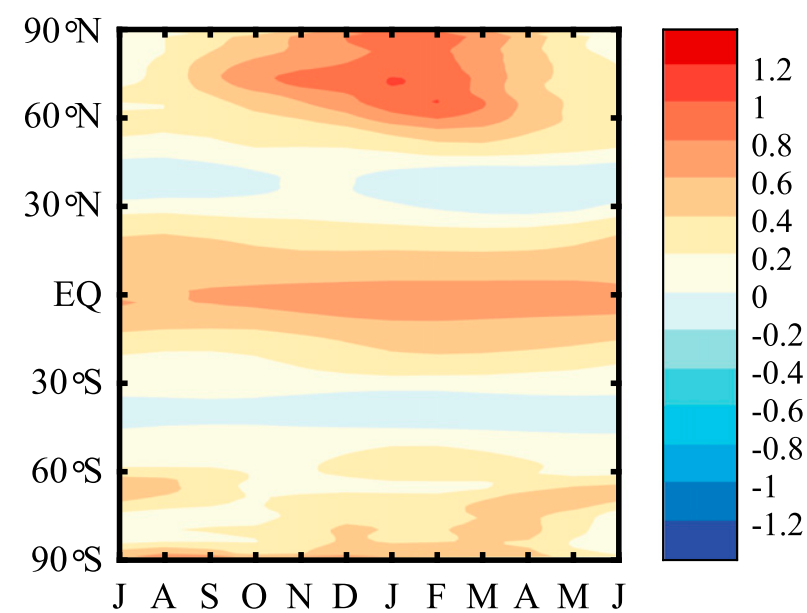

FIG. 6. Time-latitude section of the subensemble mean of decadal zonal mean SAT regression coefficients against TPI $\left(\mathrm{K} \mathrm{K}^{-1}\right)$ from 14 CMIP5 models (ACCESS1.3, BCC_CSM1.1 CanESM2, CCSM4, CMCC-CMS, CSIRO Mk3.6.0, GFDL CM3, GFDLESM2G, GFDL-ESM2M, HadGEM2-ES, MIROC-ESM, MPIESM-LR, MRI-CGCM3, NorESM1-M). These models are chosen because they can simulate a pronounced seasonality of the tropical Pacific effect in high latitudes. 
stronger in the models. The difference may be attributed to a lack of direct observations on high latitudes and/or inadequate representation of troposphere-stratosphere interactions in models (Ineson and Scaife 2009). Results with other reanalysis products and HIST simulations are similar, as the internal variability dominates on the interannual time scale.

The decadal regression in CTRL simulations (Fig. 2d) generally resembles the interannual one spatially. Instead of a sharp peak at the equator, the decadal response is more spatially uniform on the tropical Pacific. The positive response along the west coast of North America and in the Northern Hemisphere high latitudes strengthens on the decadal time scale. This is consistent with the decadal meridional correlation-regression profile in Fig. 4.

On the interannual time scale, the spatial distribution of the regression coefficient in each model is similar to the ensemble mean result shown in Fig. 2c. The largest intermodel difference is in the westward extent of the tropical Pacific maxima (Fig. 7a) related to the overly extended cold tongue in climatology. As ENSO is the dominant mode of interannual variability in the tropical Pacific, the intermodel variation in this region may induce intermodel variation of teleconnection patterns.

Intermodel variation of decadal SAT regression against TPI is smaller than the interannual one in the tropics but greater in the extratropics (Fig. 7b). Tropical Pacific SST has a robust impact on tropical SAT on the decadal time scale. In high latitudes, however, the tropical Pacific effect shows greater intermodel uncertainty and not every model shows a significant correlation with TPI. In these regions, local feedback processes (Johannessen et al. 2004; Björk et al. 2013) seem important. The intermodel variation in the high-latitude SAT response contributes to the model dependency of the TPI-GMST regression discussed in section $3 \mathrm{a}$.

\section{Tropospheric air temperature}

This section examines how the troposphere responds to tropical Pacific internal variability in the CTRL ensemble. The tropospheric temperature is estimated by integrating air temperature from the surface to the tropopause. The tropopause is estimated by the method of Reichler et al. (2003). The climatological tropopause is used at each grid point to calculate tropospheric temperature. This estimation will introduce error considering the height of the tropopause is increasing in the reanalyses (Santer et al. 2003), while it does not change the overall results related to the intermodel and timescale comparison in the CTRL ensemble.
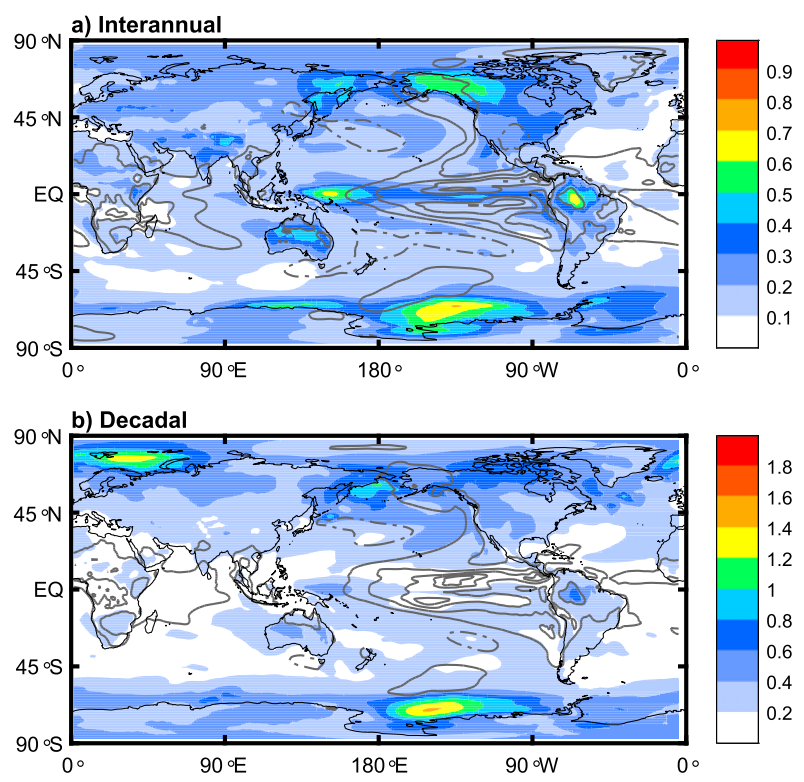

FIG. 7. Ensemble mean and intermodel variation of regression coefficients of gridded SAT against TPI $\left(\mathrm{K} \mathrm{K}^{-1}\right)$ for (a) interannual and (b) decadal variability. Shading represents the corresponding intermodel standard deviation. Note the different shading intervals between (a) and (b). Contours denote the relative ensemble mean regression coefficients (defined as the multimodel averaged regression coefficient divided by the intermodel standard deviation of the regression coefficient). The contour interval is 2 . The 0 contour is omitted for clarity.

Global mean TT (GMTT) is highly correlated (0.650.92 in the models and $0.70-0.76$ in the reanalyses) with tropical Pacific SST on the interannual time scale (Fig. 8b). The multimodel averaged correlation coefficient is 0.78 for GMTT compared to 0.77 for GMST on the interannual time scale. In the reanalysis, the multiproduct averaged correlation coefficient is 0.72 for GMTT and 0.59 for GMST. This high correlation between GMTT and TPI can also be found on the decadal time scale (coefficients ranging from 0.72 to 0.91 ; Fig. 8a) in the CTRL ensemble. The multimodel mean decadal GMTT correlation against TPI is 0.84 , larger than the TPI-GMST correlation (0.68). The intermodel variation is small for GMTT and the responses to tropical Pacific SST are robust across models.

The regression coefficients against TPI between GMTT and GMST are comparable on both interannual and decadal time scales (Figs. 8d,e), although the decadal correlation is consistently higher for GMTT than for GMST (Figs. 8a,b). The time-scale dependency is smaller in the GMTT-TPI correlation (Fig. 3a vs Fig. 8c) and regression (Fig. 3b vs Fig. 8f).

On both interannual and decadal time scales, the correlation coefficient stays high in the entire tropical troposphere, whereas the regression coefficient increases 

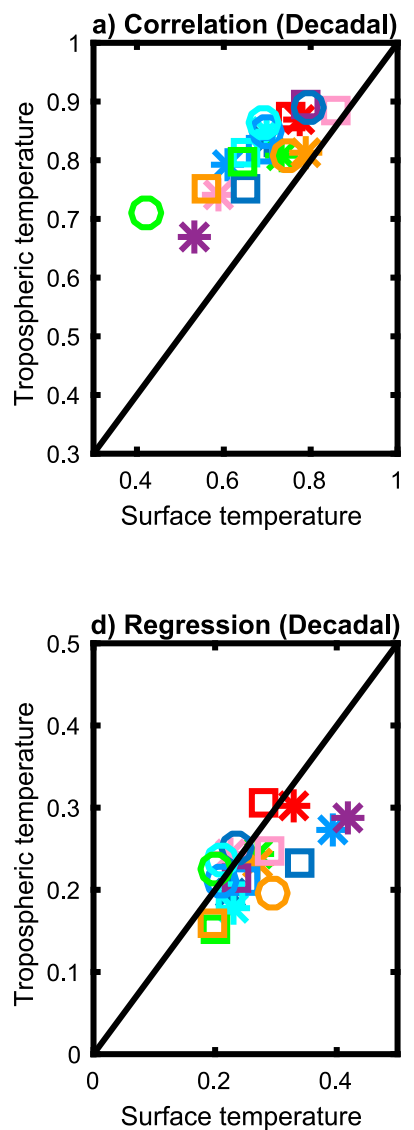
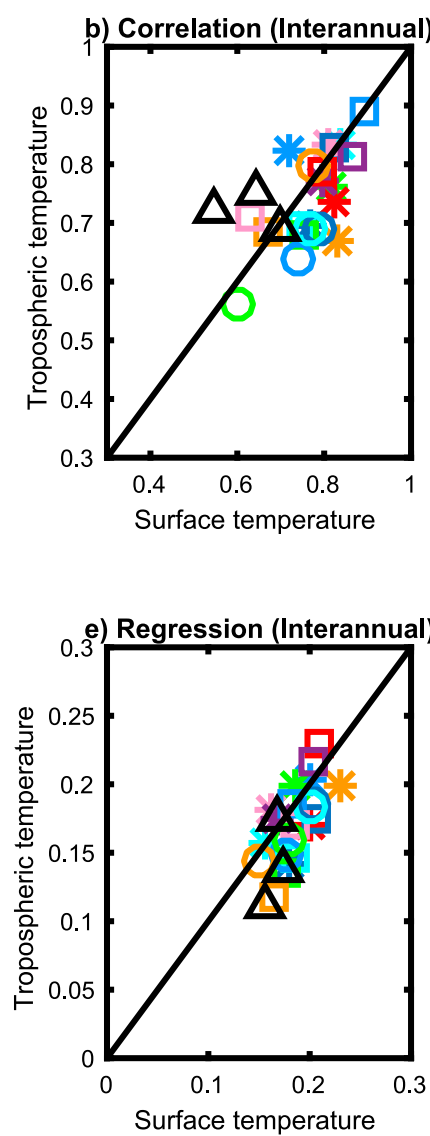
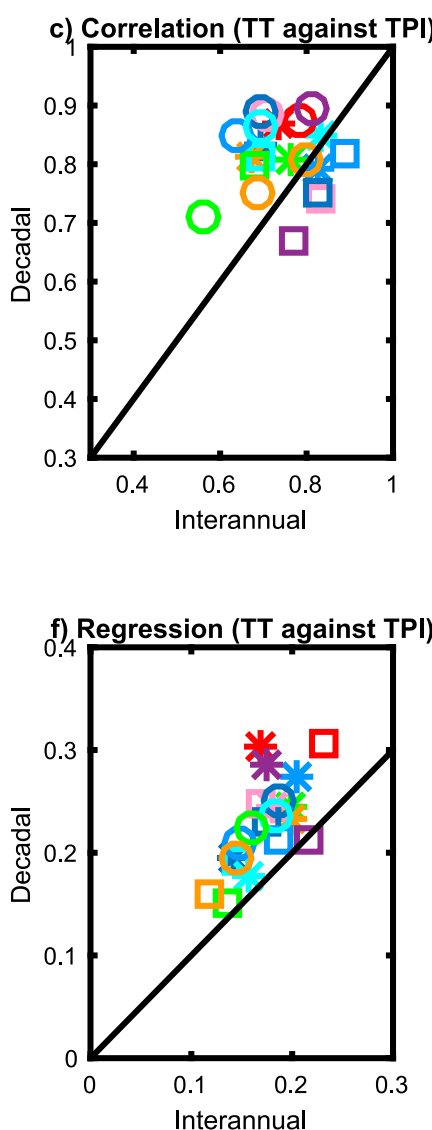

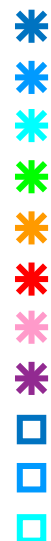

ACCESS 1.3

BCC-CSM1.1

CCSM4

CMCC-CMS

CSIRO-MK-3-6-0

CanESM2

FGOALS-G2

GFDL-CM3

GFDL-ESM2G

GFDL-ESM2M

HadGEM2-AO

HadGEM2-ES

INMCM4

IPSL-CM5A-LR

MIROC-ESM

MIROC5

MPI-ESM-LR

MPI-ESM-MR

MPI-ESM-P

MRI-CGCM3

NorESM1-M

FIG. 8. Scatterplots of (top) correlation and (bottom) regression $\left(\mathrm{K} \mathrm{K}^{-1}\right)$ coefficients for GMTT and GMST against TPI among CMIP5 models and reanalysis products. The correlation coefficients with TPI are compared against GMST and GMTT for (a) decadal variability and (b) interannual variability. (d),(e) As in (a) and (b), respectively, but for the comparison of the regression coefficient. Black triangles in (b) and (e) denote results from the three reanalysis products. (c),(f) Comparison of correlation and regression coefficients, respectively, of GMTT between time scales.

with altitude, reaching a maximum at around $300 \mathrm{hPa}$ (Fig. 9). The tropical Pacific SST effect is spread vertically over the troposphere by deep convection and horizontally in the equatorial belt by equatorial wave adjustments (Sobel et al. 2001; Trenberth and Smith 2006; Johnson and Xie 2010). This dynamical flattening effect on TT applies to all time scales, explaining the weaker time-scale dependency of TPI correlationregression for GMTT than for GMST. While we notice that GMTT lags TPI when analyzed with monthly data (Santer et al. 2001; Trenberth and Smith 2006), the intermodel and time-scale characteristics are qualitatively similar to the annual mean analysis.

The tropical Pacific impact on TT is also confined to the tropics (Fig. 10). Instead of a sharp peak at the equator for SAT, TT correlation coefficients show a broad plateau between $25^{\circ} \mathrm{S}$ and $25^{\circ} \mathrm{N}$, consistent with a weak temperature gradient in TT within the tropics due to rapid equatorial wave action. At almost all latitudes, the decadal regression coefficients are greater than the interannual ones for TT, contributing to the larger decadal regression coefficients for GMTT. In polar regions, the TT regression profile generally follows the correlation coefficients (Fig. 10), with large loading at low levels (Fig. 9). On the interannual time scale, reanalysis-model differences are found in the Northern Hemisphere polar region, with TT correlation coefficients larger in the CTRL ensemble.

Intermodel variation in TT correlation is weak in the tropics and increases gradually with latitude (Fig. 10). The intermodel spread of the regression profile, on the other hand, is almost latitude independent for both interannual and decadal variability.

\section{Implications for POGA pacemaker experiments}

So far in this paper we focus on the internal variability of tropical Pacific SST and its global effect on 

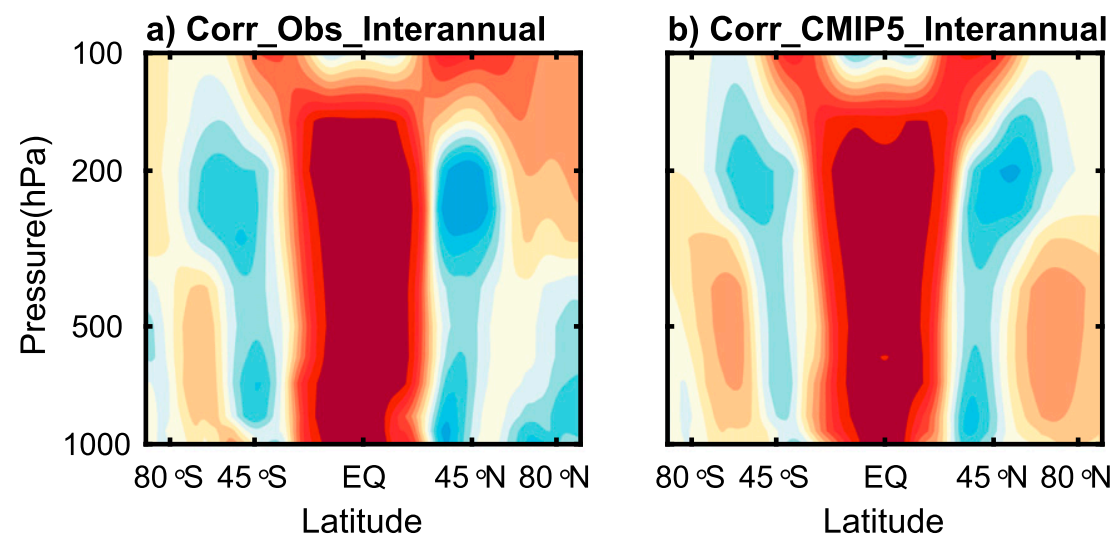
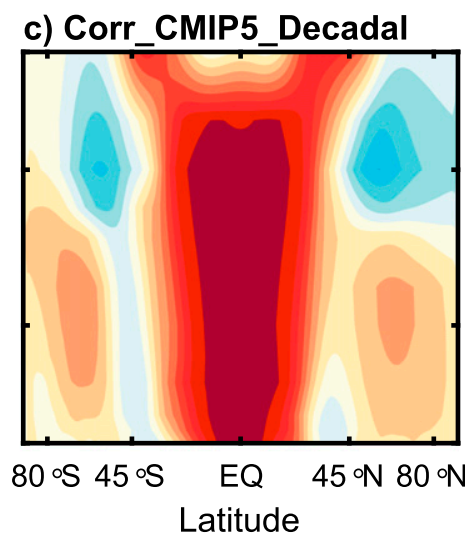
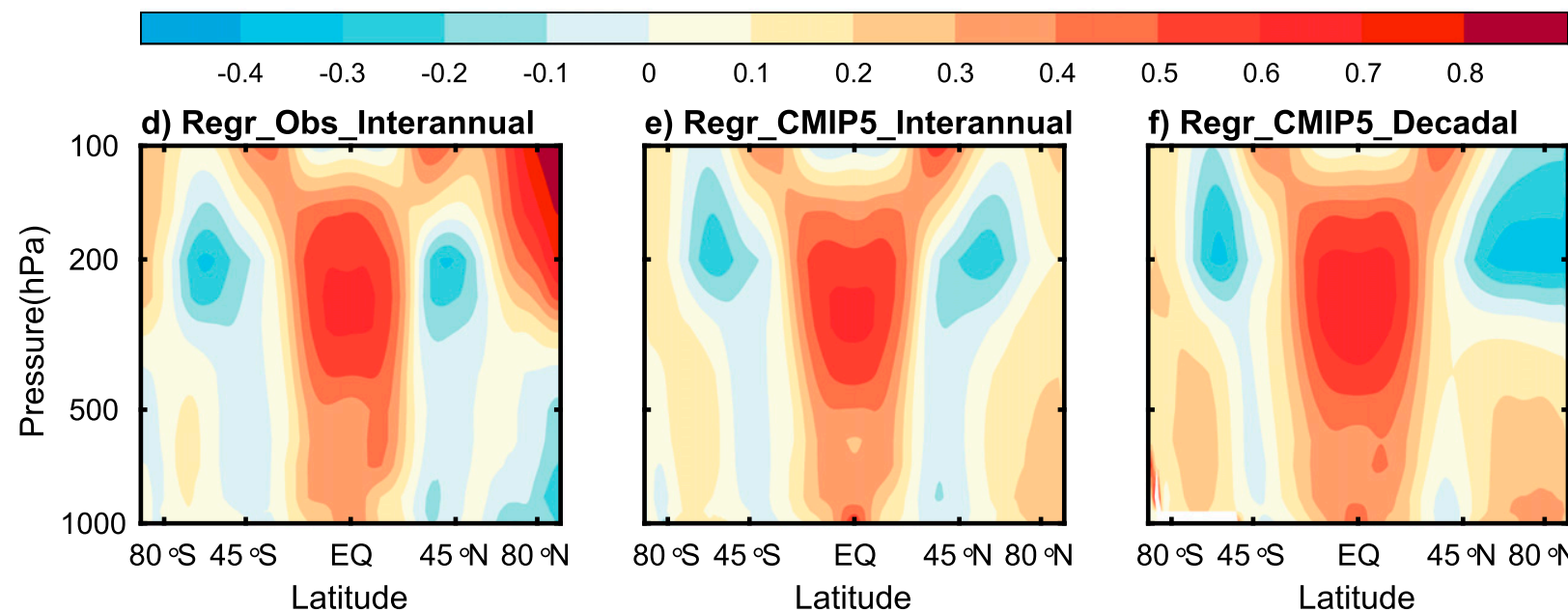

e) Regr_CMIP5_Interannual
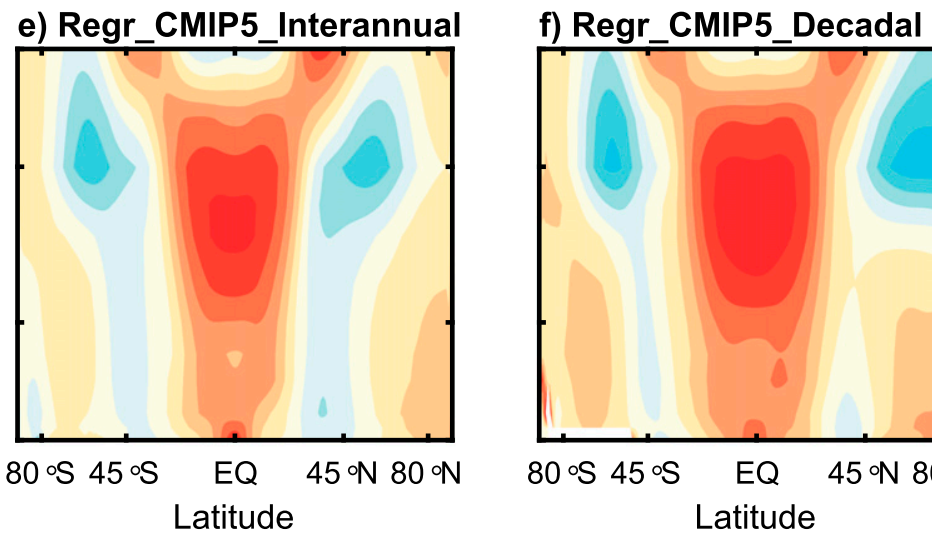

\begin{tabular}{|llllllllllllll}
\hline-0.6 & -0.45 & -0.3 & -0.15 & 0 & 0.15 & 0.3 & 0.45 & 0.6 & 0.75 & 0.9 & 1.05 & 1.2 &
\end{tabular}

FIG. 9. Meridional sections of (a)-(c) correlation and (d)-(f) regression $\left(\mathrm{K} \mathrm{K}^{-1}\right)$ of the zonal mean air temperature against TPI on the interannual time scale for the (a),(d) reanalysis products and in (b),(e) interannual and (c),(f) decadal time scales for the 21 CMIP5 ensemble mean.

SAT and TT. This section relates these results to POGA pacemaker experiments. External forcings related to changes in greenhouse gases and volcanic aerosol loadings affect global SAT and TT (Santer et al. 2001; Wigley et al. 2005; Thompson et al. 2009). Quantifying the relative contribution of the internal and external components to the global warming slowdown is beyond the scope of this study, but the presence of the external forcing may alter the statistical relationships between TPI and GMST by affecting tropical Pacific SST (Santer et al. 2015; Song and Yu 2015) and by introducing "interaction terms" between the internal and external components (Maher et al. 2015).

The POGA experiment prescribes observed SST variability in the tropical Pacific, which includes internal and forced components. In this paper, we estimate the internal variability in the POGA simulations by subtracting the HIST ensemble mean from each POGA run. A simple subtraction will introduce errors, even if we ignore the interaction terms between the internal and external components, because the ensemble mean may not accurately simulate the external forcing effect. Here we evaluate how imperfect removal of external signals may introduce errors in decadal trends in the POGA experiment.

GMST change $T$ includes the forced $F$ and internal $I$ components, $T=T_{F}+T_{I}$. Here

$$
T_{I}=a_{I} P_{I}+\varepsilon,
$$

where $P$ denotes TPI, $a$ is the GMST regression against TPI, and $\varepsilon$ denotes the remaining variability. The observed decadal variability in TPI includes both forced change $P_{F}$ and internal $P_{I}$ components. If a model simulates the forced change precisely, it will correctly 

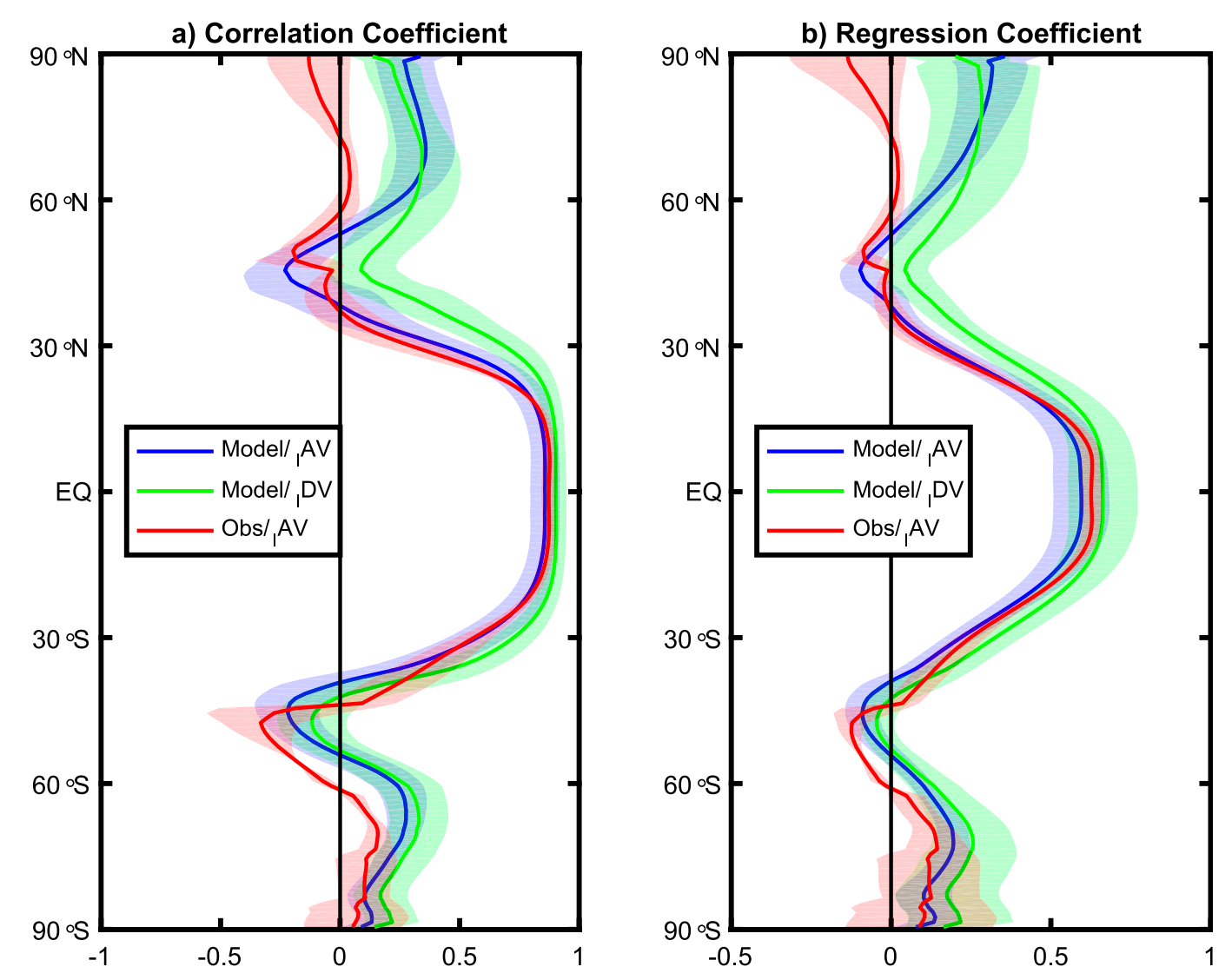

FIG. 10. As in Fig. 4, but for the (a) correlation and (b) regression coefficients of zonal mean TT against TPI.

capture $P_{I}$ from the prescribed observations. As model errors are inevitable in simulating the forced change $\left(\Delta P_{F}=P_{F}-P_{\mathrm{FM}}\right.$ is the error, with the subscript FM denoting the model result), the POGA experiment interprets $P_{F}^{\prime}=P_{I}-\Delta P_{F}$ as "internal" variability.

The forced SAT change is spatially uniform in sign (Fig. S3 in the supplemental material file JCLI-D-150496s1) and GMST scales with the tropical Pacific SST change $\left(T_{F}=a_{F} P_{F}\right.$ with $a_{F}=1.26$ in CM2.1). From the fact that the forced and internal decadal changes in GMST are comparable in magnitude $\left[O\left(T_{I}\right) \sim O\left(T_{F}\right)\right]$ in the recent surface warming slowdown, we estimate the order of magnitude of $P_{F}=$ $\left(1 / a_{F}\right) T_{F} \approx\left(1 / a_{F}\right) T_{I}=\left(a_{I} / a_{F}\right) P_{I}$. Namely, the forced component of the recent decadal change in TPI is a small fraction of the internal component, which is hardly surprising. In CM2.1, $a_{F}=1.26$ and $a_{I}=0.28$. Thus, a $30 \%$ model error in $P_{F}$ results in only a $7 \%$ error in estimating internal tropical Pacific SST variability $\left(\Delta P_{F} / P_{I}=0.3 P_{F} / P_{I}=0.3 a_{I} / a_{F} \approx 0.07\right)$. The small effect of errors in simulating the forced Pacific change on the model interpretation of internal TPI variability indicates that the TPI-GMST regression derived from unforced control runs is a good approximation for the tropical Pacific pacemaker effect in the POGA experiment.

\section{Summary}

Using outputs from 21 CMIP5 models and three reanalyses, we have evaluated the impact of tropical $\mathrm{Pa}-$ cific variability on global SAT and TT. A tropical Pacific index is defined to capture the dominant mode of the tropical Pacific and is used for a quantitative comparison between observations and the multimodel ensemble.

The tropical Pacific effect on SAT is mainly confined to the tropics. On the interannual time scale, GMST is highly correlated with tropical Pacific SST, consistent with the widely recognized global impact of ENSO. CMIP5 models overestimate the quantitative relationship between GMST and tropical Pacific SST, an error that can be traced back to the excessive westward extension of the cold tongue on the equator and a warming in the Northern Hemisphere polar regions. The decadal correlation between tropical Pacific SST and GMST is relatively weak, owing to the opposing patterns in the zonal direction in the mid- and high latitudes. The GMST regression against TPI is greater in magnitude for decadal than interannual 
variability because of a broader meridional structure in the tropics and a larger contribution from extratropical regions. In boreal winter, the tropical Pacific effect on polar/subpolar SAT in the Northern Hemisphere intensifies because of enhanced eddy mixing between the tropics and pole. This contributes to the strong seasonality of the observed global warming slowdown.

The statistical relationship between tropical Pacific SST and GMST displays model and time-scale dependency, especially in high latitudes. The large intermodel spread of the regression coefficient suggests that the effectiveness of the POGA experiments in simulating the global warming slowdown is model dependent. The time-scale dependency, on the other hand, indicates that observational estimates of the tropical Pacific effect on GMST based on interannual variability may be biased low for decadal variability, such as the recent surface warming slowdown. We have shown that the POGAHIST difference well represents the effect of internal tropical Pacific variability. Indeed, Kosaka and Xie (2016) proposed a method to derive anthropogenic GMST change from observations by using the POGA pacemaker experiments to estimate internal variability.

Compared to GMST, GMTT shows a more robust correlation with tropical Pacific SST with smaller differences on statistics between the interannual and decadal time scales. The intermodel variations are also smaller than the results for SAT. The meridional profiles of correlation and regression suggest that the tropical Pacific effect on TT is confined to the tropical to subtropical regions. The TT response is meridionally broad and upward amplified as a result of fast equatorial wave propagation and moist convection, respectively. In contrast, tropical Pacific SST variability peaks sharply on the equator due to the effects of equatorial upwelling and thermocline feedback (Neelin et al. 1998). The threedimensional TT structure explains why the TT correlation with TPI is nearly insensitive to time scales and is higher than the SAT correlation on the decadal time scale.

Acknowledgments. We wish to thank Dr. Ben Santer and two anonymous reviewers for their constructive comments, which helped improve the paper. This work was supported by the National Basic Research Program of China (2012CB955600), the National Key Research and Development Program of China (2016YFA0601804), the Natural Science Foundation of China (NSFC) Major Project (41490640 and 41490643), the NSFC-Shandong Joint Fund for Marine Science Research Centers (U1406401), and the U.S. National Science Foundation (1637450). Yu Kosaka is supported by the Japanese Ministry of Education, Culture, Sports, Science and Technology through Grant-in-Aid for Young Scientists

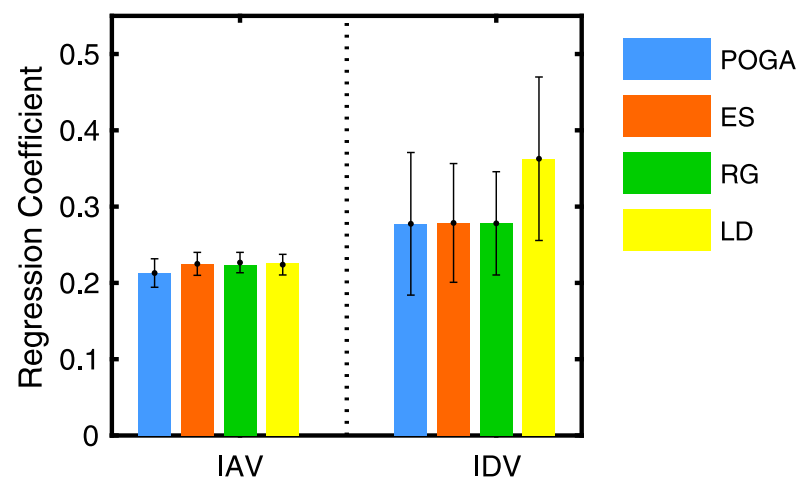

FIG. A1. Regression coefficients $\left(\mathrm{K} \mathrm{K}^{-1}\right)$ of GMST against TPI with different methods to extract the internal variability on interannual and decadal time scales. Error bars represent intermember standard deviation.

(15H05466) and the Arctic Challenge for Sustainability (ArCS) Project, and by the Japanese Ministry of Environment through the Environment Research and Technology Development Fund 2-1503. The World Climate Research Programme's Working Group on Coupled Modelling is responsible for CMIP, and we thank the climate modeling groups for producing and making available the model output. For CMIP the U.S. Department of Energy's Program for Climate Model Diagnosis and Intercomparison provides coordinating support and led development of software infrastructure in partnership with the Global Organization for Earth System Science Portals.

\section{APPENDIX A}

\section{Comparison of Methods that Remove External Signals}

The effect of internal TPI variability can be estimated from HIST runs. Here, we use 10 POGA runs and 20 HIST runs with GFDL CM2.1 to illustrate how different methods employed to remove external signals affect the tropical Pacific.

The HIST simulations include both radiative forcing and internal variability. The latter can be estimated by subtracting the 20-member GFDL CM2.1 HIST ensemble mean from each individual HIST realization (ES). There are two ways to extract internal variability when the multimember ensemble is not available for HIST simulations (as for many CMIP5 models). A simple linear detrending (LD) removes an approximate forced component, and a method proposed by Dai et al. (2015) that uses the linear regression against the multimodel ensemble mean of GMST anomaly ( $R G)$ is used to isolate the internal variability. Figures A1, A2 compare the global mean and spatial 
a) IAV: POGA

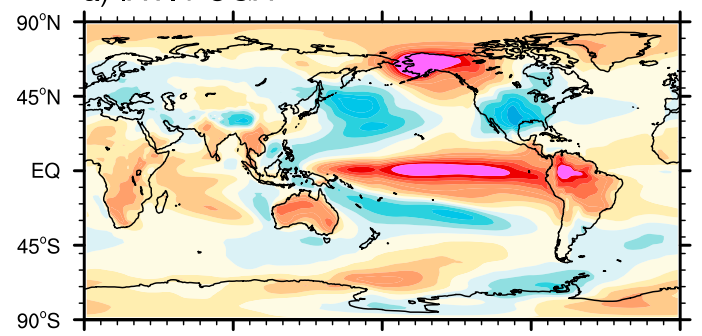

c) IAV: ES

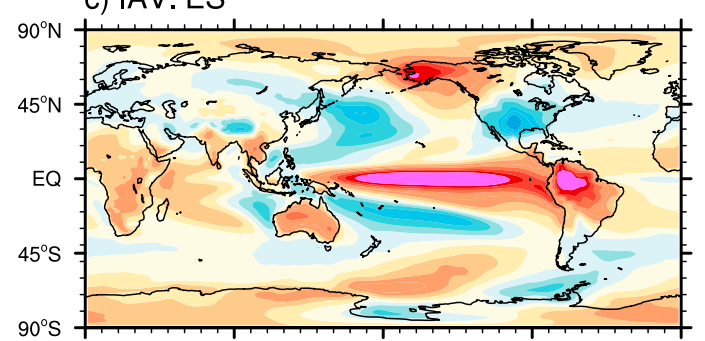

e) IAV: RG
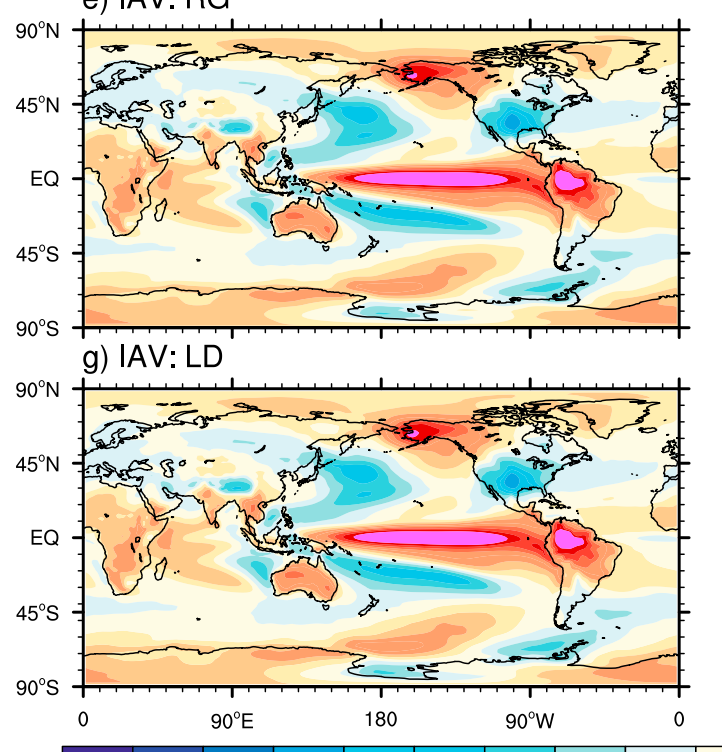

b) IDV: POGA

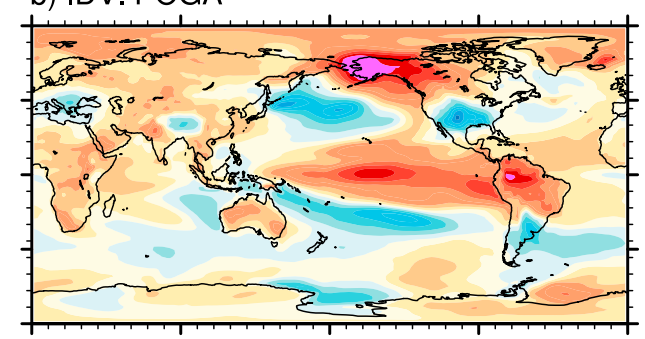

d) IDV: ES
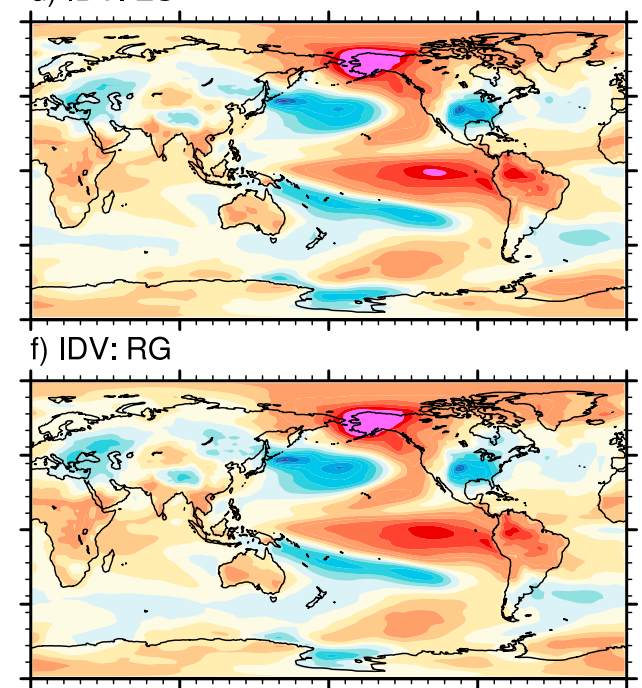

h) IDV: LD

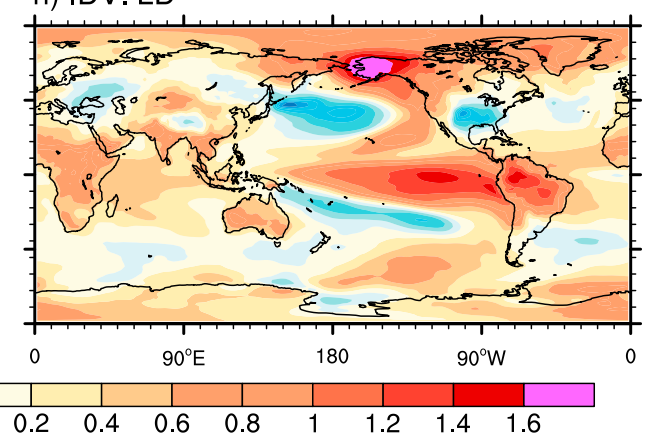

FIG. A2. Multimember averaged regression coefficients $\left(\mathrm{K} \mathrm{K}^{-1}\right)$ of gridded SAT against TPI on (left) IAV and (right) IDV time scales in the GFDL CM2.1 (a),(b) POGA and (c)-(h) HIST simulations. The ES, RG, and LD denote the methods used to remove external forcings.

pattern of TPI-SAT regression with different extraction methods.

Dominated by ENSO, the horizontal distribution of the regression coefficient shows no significant difference on the interannual time scale among forced signal removal methods [Figs. A2(c),(e),(g)]. The tropical Pacific impact on the GMST is also comparable among all three methods (Fig. A1) and quantitatively similar to the POGA result. On the decadal time scale, the three methods also give similar regression patterns (Figs. 2d,f,h) but the LD method has a larger response across the globe (Fig. S4 in the supplemental material file JCLI-D-15-0496s1). Because of nonlinear variations in radiative forcing (e.g., the increase rate of $\mathrm{CO}_{2}$ accelerated around 1970), the residual "internal variability" obtained by the LD method includes a considerable forced component. This forced component increases the decadal GMST regression coefficient by $30 \%$ compared to the other two methods. It also increases the standard deviation of the decadal tropical Pacific SST in LD, erroneously by $\sim 12 \%$ and $5 \%$ compared to ES and ER, respectively. 
a) IDV: Corr-STD(TPI)

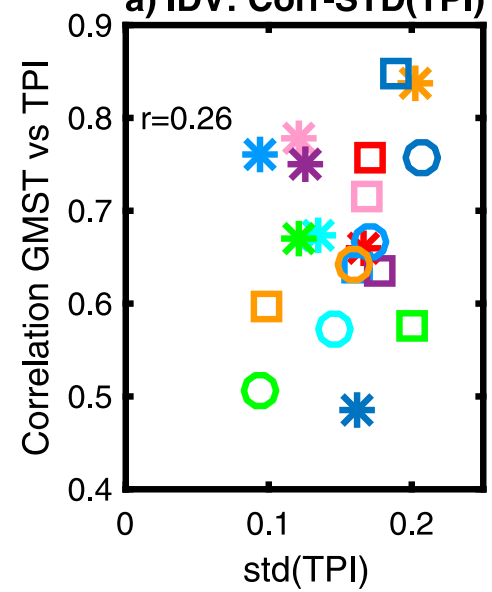

c) IDV: Regr-STD(TPI)

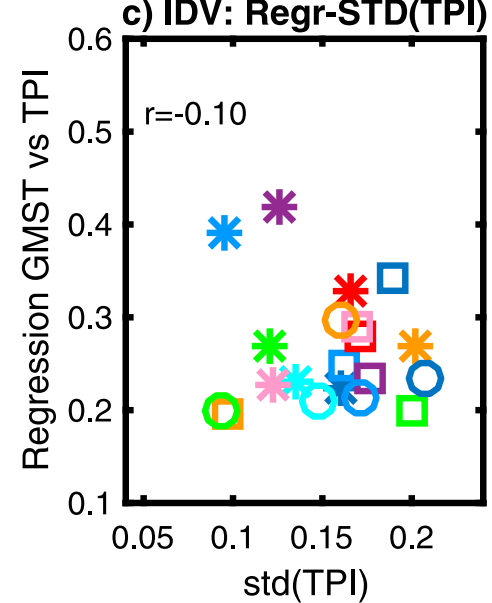

b) IAV: Corr-STD(TPI)
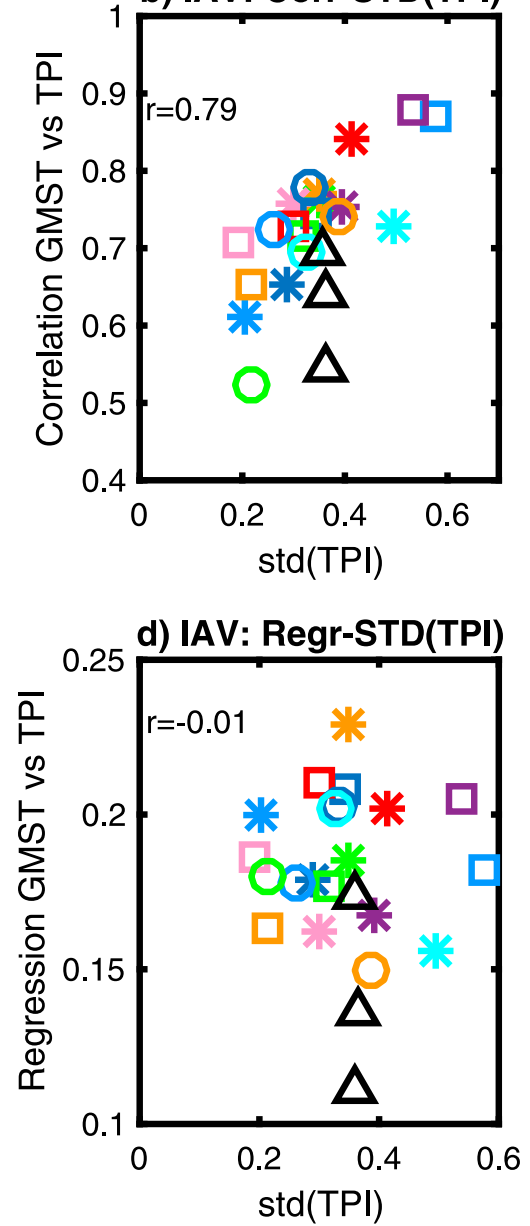

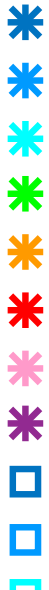

ACCESS1.3

BCC-CSM1.1

CCSM4

CMCC-CMS

CSIRO-MK-3-6-0

CanESM2

FGOALS-G2

GFDL-CM3

GFDL-ESM2G

GFDL-ESM2M

HadGEM2-AO

HadGEM2-ES

INMCM4

IPSL-CM5A-LR

MIROC-ESM

MIROC5

MPI-ESM-LR

MPI-ESM-MR

MPI-ESM-P

MRI-CGCM3

NorESM1-M

FIG. A3. Scatterplots between TPI amplitude measured as its standard deviation and GMST-TPI correlation in (a) IDV and (b) IAV time scales. (c),(d) As in (a) and (b), respectively, but for regression coefficients ( $\mathrm{K} \mathrm{K}^{-1}$ ) of GMST against TPI instead of correlation. Black triangles in (b) and (d) denote results from the three reanalysis products.

The GMST-TPI regression coefficient is sensitive to the choice of method for extracting internal variability from the models and reanalysis datasets, especially on the decadal time scale. If the ensemble size is large enough, then both the ES and RG methods provide reasonable estimates of internal variability for the HIST simulations. When only one single run is available for HIST as is for many CMIP5 models, the ES method cannot be used, while RG still provides a reasonable estimate of internal variability.

\section{APPENDIX B}

\section{TPI Amplitude and GMST Regression}

The simulated ENSO varies in amplitude and power spectrum among CMIP5 models (Bellenger et al. 2014). Some models overestimate the ENSO amplitude (e.g., CCSM4; Deser et al. 2012). The intermodel variation in TPI amplitude may contribute to the intermodel uncertainty of the GMST-TPI regression.

Tropical Pacific SST variability in the CMIP5 CTRL simulations is smaller in magnitude than in the reanalyses and HIST simulations. In 17 out of 21 models, tropical Pacific variability in CTRL simulations is weak compared to ERSST. The correlation coefficient between interannual GMST and TPI tends to increase with TPI variance in the CTRL (Figs. A3a,b). The regression coefficients are not sensitive to TPI variance, however (Figs. A3c,d).

Three models with the largest decadal regression coefficients (GFDL CM3, BCC_CSM1.1, and GFDLESM2G) have relatively small TPI amplitudes. We exclude the three outliers and then divide the remaining CMIP5 ensemble into two groups (labeled as "strong" and "weak"; Table 1) according to interannual standard deviation of TPI. The GMST 


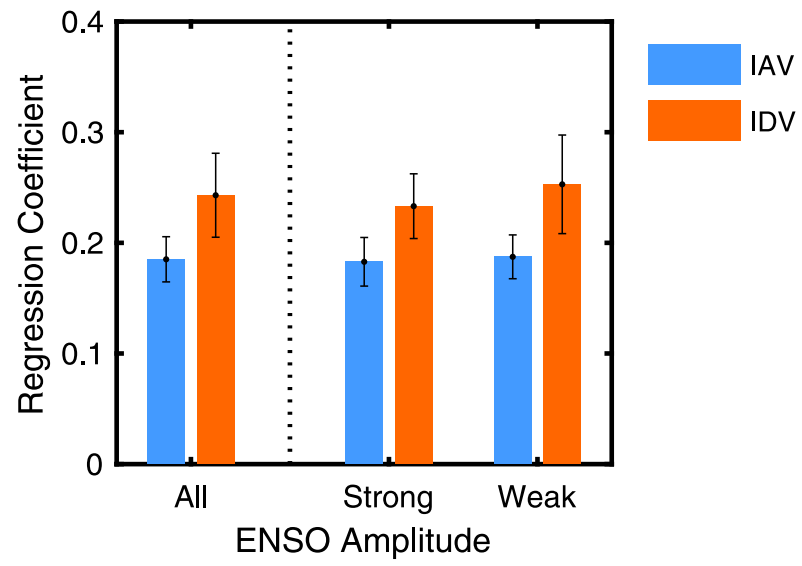

FIG. A4. Regression coefficients $\left(\mathrm{K} \mathrm{K}^{-1}\right)$ of GMST against TPI in the whole ensemble of 18 CMIP5 (three outliers excluded) CTRL simulations (All), strong ENSO group (strong) and weak ENSO group (weak) on interannual and decadal time scales. Error bars represent intermember standard deviation.

regression coefficients against TPI for the strong and weak ENSO subensembles are 0.183 and 0.187 , respectively, on the interannual time scale. On the decadal time scale, the regression coefficients are 0.233 and 0.252 , respectively. These differences between the two subensembles are smaller than the intermodel variations within each subensemble (Fig. A4). The patterns of global SAT regression against TPI are also similar for the two groups (not shown) on both time scales. In the CTRL simulations, the tropical SST impact on the GMST measured by regression is insensitive to the ENSO amplitude.

\section{REFERENCES}

Balmaseda, M. A., K. E. Trenberth, and E. Källén, 2013: Distinctive climate signals in reanalysis of global ocean heat content. Geophys. Res. Lett., 40, 1754-1759, doi:10.1002/grl.50382.

Bellenger, H., E. Guilyardi, J. Leloup, M. Lengaigne, and J. Vialard, 2014: ENSO representation in climate models: From CMIP3 to CMIP5. Climate Dyn., 42, 1999-2018, doi:10.1007/s00382-013-1783-z.

Bindoff, N., and Coauthors, 2013: Detection and attribution of climate change: From global to regional. Climate Change 2013: The Physical Science Basis, T. F. Stocker et al., Eds., Cambridge University Press, 867-952.

Björk, G., C. Stranne, and K. Borenäs, 2013: The sensitivity of the Arctic Ocean sea ice thickness and its dependence on the surface albedo parameterization. J. Climate, 26, 1355-1370, doi:10.1175/JCLI-D-12-00085.1.

Boer, G. J., and Coauthors, 2016: The Decadal Climate Prediction Project (DCPP) contribution to CMIP6. Geosci. Model Dev., 9, 3751-3777, doi:10.5194/gmd-9-3751-2016.

Brown, P., W. Li, and S.-P. Xie, 2015: Regions of significant influence on unforced global mean surface air temperature variability in climate models. J. Geophys. Res. Atmos., 120, 480-494, doi:10.1002/2014JD022576.
Chen, X., and K.-K. Tung, 2014: Varying planetary heat sink led to global-warming slowdown and acceleration. Science, 345, 897903, doi:10.1126/science.1254937.

Chylek, P., J. D. Klett, G. Lesins, M. K. Dubey, and N. Hengartner, 2014: The Atlantic Multidecadal Oscillation as a dominant factor of oceanic influence on climate. Geophys. Res. Lett., 41, 1689-1697, doi:10.1002/2014GL059274.

Dai, A., J. C. Fyfe, S.-P. Xie, and X. Dai, 2015: Decadal modulation of global surface temperature by internal climate variability. Nat. Climate Change, 5, 555-559, doi:10.1038/nclimate2605.

Dee, D. P., and Coauthors, 2011: The ERA-Interim reanalysis: Configuration and performance of the data assimilation system. Quart. J. Roy. Meteor. Soc., 137, 553-597, doi:10.1002/qj.828.

Delworth, T. L., and Coauthors, 2006: GFDL's CM2 global coupled climate models. Part I: Formulation and simulation characteristics. J. Climate, 19, 643-674, doi:10.1175/JCLI3629.1.

Deser, C., and Coauthors, 2012: ENSO and Pacific decadal variability in Community Climate System Model version 4. J. Climate, 25, 2622-2651, doi:10.1175/JCLI-D-11-00301.1.

Domingues, C. M., J. A. Church, N. J. White, P. J. Gleckler, S. E. Wijffels, P. M. Barker, and J. R. Dunn, 2008: Improved estimates of upper-ocean warming and multi-decadal sea-level rise. Nature, 453, 1090-1094, doi:10.1038/nature07080.

Easterling, D. R., and M. F. Wehner, 2009: Is the climate warming or cooling? Geophys. Res. Lett., 36, L08706, doi:10.1029/ 2009GL037810.

England, M. H., and Coauthors, 2014: Recent intensification of winddriven circulation in the Pacific and the ongoing warming hiatus. Nat. Climate Change, 4, 222-227, doi:10.1038/nclimate2106.

Fasullo, J. T., and K. E. Trenberth, 2008: The annual cycle of the energy budget. Part II: Meridional structures and poleward transports. J. Climate, 21, 2313-2325, doi:10.1175/2007JCLI1936.1.

Foster, G., and S. G. Rahmstorf, 2011: Global temperature evolution 1979-2010. Environ. Res. Lett., 6, 044022, doi:10.1088/ $1748-9326 / 6 / 4 / 044022$.

Fyfe, J. G., and Coauthors, 2016: Making sense of the early-2000s global warming slowdown. Nat. Climate Change, 6, 224-228, doi:10.1038/nclimate2938.

Gleckler, P. J., and Coauthors, 2012: Human-induced global ocean warming on multidecadal timescales. Nat. Climate Change, 2 , 524-529, doi: $10.1038 /$ nclimate 1553 .

Hansen, J., and Coauthors, 2005: Earth's energy imbalance: Confirmation and implications. Science, 308, 1431-1435, doi:10.1126/ science. 1110252.

Ineson, S., and A. A. Scaife, 2009: The role of the stratosphere in the European climate response to El Niño. Nat. Geosci., 2, 32 36, doi:10.1038/ngeo381.

Johannessen, O. M., and Coauthors, 2004: Arctic climate change: Observed and modeled temperature and sea-ice variability. Tellus, 56A, 559-560, doi:10.1111/j.1600-0870.2004.00092.x.

Johnson, N. C., and S.-P. Xie, 2010: Changes in the sea surface temperature threshold for tropical convection. Nat. Geosci., $\mathbf{3}$, 842-845, doi:10.1038/ngeo1008.

Kalnay, E., and Coauthors, 1996: The NCEP/NCAR 40-Year Reanalysis Project. Bull. Amer. Meteor. Soc., 77, 437-470, doi:10.1175/1520-0477(1996)077<0437:TNYRP>2.0.CO;2.

Kaufmann, R. K., H. Kauppi, M. L. Mann, and J. H. Stock, 2011: Reconciling anthropogenic climate change with observed temperature 1998-2008. Proc. Natl. Acad. Sci. USA, 108, 11 790-11793, doi:10.1073/pnas.1102467108.

Kobayashi, S., and Coauthors, 2015: The JRA-55 Reanalysis: General specifications and basic characteristics. J. Meteor. Soc. Japan, 93, 5-48, doi:10.2151/jmsj.2015-001. 
Kopp, G., and J. L. Lean, 2011: A new, lower value of total solar irradiance: Evidence and climate significance. Geophys. Res. Lett., 38, L01706, doi:10.1029/2010GL045777.

Kosaka, Y., and S.-P. Xie, 2013: Recent global-warming hiatus tied to equatorial Pacific surface cooling. Nature, 501, 403-407, doi:10.1038/nature12534.

— , and - 2016: The tropical Pacific as a key pacemaker of the variable rates of global warming. Nat. Geosci., 9, 669-673, doi:10.1038/ngeo2770.

Laepple, T., and P. Huybers, 2014: Ocean surface temperature variability: Large model-data differences at decadal and longer periods. Proc. Natl. Acad. Sci. USA, 111, 16682-16687, doi:10.1073/pnas.1412077111.

Levitus, S., and Coauthors, 2012: World ocean heat content and thermosteric sea level change $(0-2000 \mathrm{~m}), 1955-2010$. Geophys. Res. Lett., 39, L10603, doi:10.1029/2012GL051106.

Liu, W., S.-P. Xie, and J. Lu, 2016: Tracking ocean heat uptake during the surface warming hiatus. Nat. Commun., 7, 10926, doi:10.1038/ncomms10926.

Loeb, N. G., J. M. Lyman, G. C. Johnson, R. P. Allen, D. R Doelling, T. Wong, B. J. Soden, and G. L. Stephens, 2012: Observed changes in top-of-the-atmosphere radiation and upper-ocean heating consistent within uncertainty. Nat. Geosci., 5, 110-113, doi:10.1038/ngeo1375.

Lyman, J. M., S. A. Good, V. V. Gouretski, M. Ishii, G. C. Johnson, M. D. Palmer, D. M. Smith, and J. K. Willis, 2010: Robust warming of the global upper ocean. Nature, 465, 334-337, doi:10.1038/nature09043.

Maher, N., S. McGregor, M. H. England, and A. Sen Gupta, 2015: Effects of volcanism on tropical variability. Geophys. Res. Lett., 42, 6024-6033, doi:10.1002/2015GL064751.

Meehl, G. A., J. M. Arblaster, J. T. Fasullo, A. Hu, and K. E. Trenberth, 2011: Model-based evidence of deep-ocean heat uptake during surface-temperature hiatus periods. Nat. Climate Change, 1, 360-364, doi:10.1038/nclimate1229.

_ , A. Hu, J. M. Arblaster, J. Fasullo, and K. E. Trenberth, 2013: Externally forced and internally generated decadal climate variability associated with the interdecadal Pacific oscillation. J. Climate, 26, 7298-7310, doi:10.1175/JCLI-D-12-00548.1.

Neelin, J. D., D. S. Battisti, A. C. Hirst, F.-F. Jin, Y. Wakata, T. Yamagata, and S. E. Zebiak, 1998: ENSO theory. J. Geophys. Res., 103, 14 261-14 290, doi:10.1029/97JC03424.

Power, S., T. Casey, C. Folland, A. V. Colman, and V. Mehta, 1999: Inter-decadal modulation of the impact of ENSO on Australia. Climate Dyn., 15, 319-324, doi:10.1007/s003820050284.

Reichler, T., M. Dameris, and R. Sausen, 2003: Determining the tropopause height from gridded data. Geophys. Res. Lett., $\mathbf{3 0}$, 2042, doi:10.1029/2003GL018240.

Santer, B. D., and Coauthors, 2001: Accounting for the effects of volcanoes and ENSO in comparisons of modeled and observed temperature trends. J. Geophys. Res., 106, $28033-$ 28 059, doi:10.1029/2000JD000189.

- , and Coauthors, 2003: Contributions of anthropogenic and natural forcing to recent tropopause height changes. Science, 301, 479-483, doi:10.1126/science.1084123.

— , and Coauthors, 2011: Separating signal and noise in atmospheric temperature changes: The importance of timescale. J. Geophys. Res., 116, D22105, doi:10.1029/2011JD016263.

- , and Coauthors, 2013: Identifying human influences on atmospheric temperature. Proc. Natl. Acad. Sci. USA, 110, 2633, doi:10.1073/pnas.1210514109.
— , and Coauthors, 2014: Volcanic contribution to decadal changes in tropospheric temperature. Nat. Geosci., 7, 185-189, doi:10.1038/ngeo2098.

— , and Coauthors, 2015: Observed multivariable climate signals of late 20th and early 21st century volcanic activity. Geophys. Res. Lett., 42, 500-509, doi:10.1002/2014GL062366.

Smith, T. M., R. W. Reynolds, T. C. Peterson, and J. Lawrimore, 2008: Improvements to NOAA's historical merged landocean surface temperature analysis (1880-2006). J. Climate, 21, 2283-2296, doi:10.1175/2007JCLI2100.1.

Sobel, A. H., J. Nilsson, and L. M. Polvani, 2001: The weak temperature gradient approximation and balanced tropical moisture waves. J. Atmos. Sci., 58, 3650-3665, doi:10.1175/ 1520-0469(2001)058<3650:TWTGAA $>2.0 . C O ; 2$.

Solomon, S., J. S. Daniel, R. R. Neely III, J.-P. Vernier, E. G. Dutton, and L. W. Thomason, 2011: The persistently variable "background" stratospheric aerosol layer and global climate change. Science, 333, 866-870, doi:10.1126/science.1206027.

Song, Y., and Y. Yu, 2015: Impacts of external forcing on the decadal climate variability in CMIP5 simulations. J. Climate, $\mathbf{2 8}$, 5389-5405, doi:10.1175/JCLI-D-14-00492.1.

Steinman, B. A., M. E. Mann, and S. K. Miller, 2015: Atlantic and Pacific multidecadal oscillations and Northern Hemisphere temperatures. Science, 347, 988-991, doi:10.1126/science.1257856.

Taylor, K. E., R. J. Stouffer, and G. A. Meehl, 2012: An overview of the CMIP5 experiment design. Bull. Amer. Meteor. Soc., 93, 485-498, doi:10.1175/BAMS-D-11-00094.1.

Thompson, D. W. J., J. Wallace, P. Jones, and J. Kennedy, 2009: Identifying signatures of natural climate variability in time series of global-mean surface temperature: Methodology and insights. J. Climate, 22, 6120-6141, doi:10.1175/ 2009JCLI3089.1.

Trenberth, K. E., 2015: Has there been a hiatus? Science, 349, 691-692, doi:10.1126/science.aac9225.

- and L. Smith, 2006: The vertical structure of temperature in the tropics: Different flavors of El Niño. J. Climate, 19, 49564973, doi:10.1175/JCLI3891.1.

, J. M. Caron, D. P. Stepaniak, and S. Worley, 2002: Evolution of El Niño-Southern Oscillation and global atmospheric surface temperatures. J. Geophys. Res., 107, 4065, doi:10.1029/ 2000JD000298.

- J. T. Fasullo, and J. Kiehl, 2009: Earth's global energy budget. Bull. Amer. Meteor. Soc., 90, 311-323, doi:10.1175/ 2008BAMS2634.1.

Tung, K.-K., and J. Zhou, 2013: Using data to attribute episodes of warming and cooling in instrumental records. Proc. Natl. Acad. Sci. USA, 110, 2058-2063, doi:10.1073/pnas.1212471110.

Watanabe, M., H. Shiogama, H. Tatebe, M. Hayashi, M. Ishii, and K. Kimoto, 2014: Contribution of natural decadal variability to global warming acceleration and hiatus. Nat. Climate Change, 4, 893-897, doi:10.1038/nclimate2355.

Wigley, T. M. L., C. M. Ammann, B. D. Santer, and S. C. B. Raper, 2005: The effect of climate sensitivity on the response to volcanic forcing. J. Geophys. Res., 110, D09107, doi:10.1029/ 2004JD005557.

Xie, S.-P., Y. Kosaka, and Y. M. Okumura, 2016: Distinct energy budgets for anthropogenic and natural changes during global warming hiatus. Nat. Geosci., 9, 29-33, doi:10.1038/ngeo2581

Zhang, Y., J. M. Wallace, and D. S. Battisti, 1997: ENSO-like interdecadal variability: 1900-93. J. Climate, 10, 1004-1020, doi:10.1175/1520-0442(1997)010<1004:ELIV>2.0.CO;2. 